Florida International University FIU Digital Commons

FIU Electronic Theses and Dissertations

University Graduate School

6-13-2014

\title{
Three Essays on Taxation, Growth and Consumption
}

Yi Ding

dingalpha@gmail.com

DOI: $10.25148 /$ etd.FI14071149

Follow this and additional works at: https://digitalcommons.fiu.edu/etd

\section{Recommended Citation}

Ding, Yi, "Three Essays on Taxation, Growth and Consumption" (2014). FIU Electronic Theses and Dissertations. 1496.

https://digitalcommons.fiu.edu/etd/1496

This work is brought to you for free and open access by the University Graduate School at FIU Digital Commons. It has been accepted for inclusion in FIU Electronic Theses and Dissertations by an authorized administrator of FIU Digital Commons. For more information, please contact dcc@fiu.edu. 


\section{FLORIDA INTERNATIONAL UNIVERSITY \\ Miami, Florida}

THREE ESSAYS ON TAXATION, GROWTH AND CONSUMPTION

A dissertation submitted in partial fulfillment of the

requirements for the degree of

DOCTOR OF PHILOSOPHY

in

ECONOMICS

by

Yi Ding 


\section{To: Interim Dean Michael R. Heithaus}

College of Arts and Sciences

This dissertation, written by Yi Ding, and entitled Three Essays on Taxation, Growth and Consumption, having been approved in respect to style and intellectual content, is referred to you for judgment.

We have read this dissertation and recommend that it be approved.

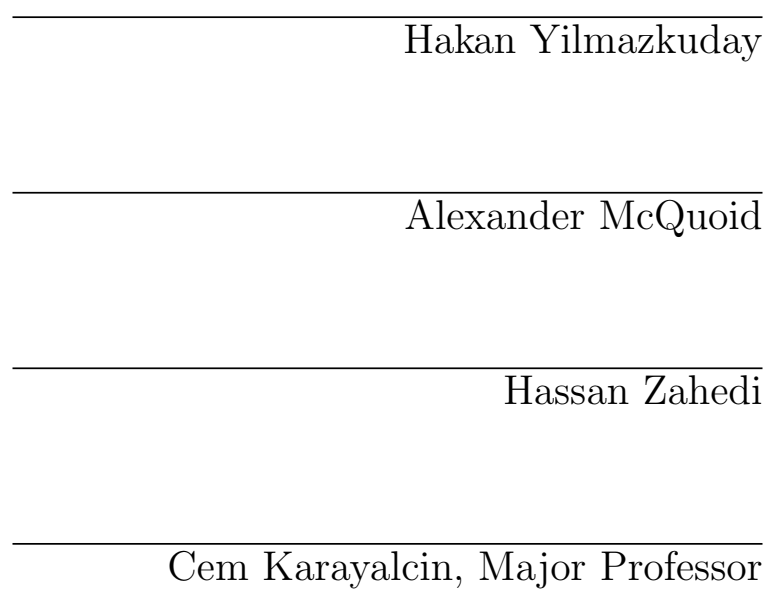

Date of Defense: June 13, 2014

The dissertation of Yi Ding is approved.

$\begin{array}{r}\hline \begin{array}{r}\text { Interim Dean Michael R. Heithaus } \\ \text { College of Arts and Sciences }\end{array} \\ \hline \begin{array}{r}\text { Dean Lakshmi N. Reddi } \\ \text { University Graduate School }\end{array}\end{array}$

Florida International University, 2014 
(C) Copyright 2014 by Yi Ding

All rights reserved. 


\section{DEDICATION}

To my parents. 


\section{ACKNOWLEDGMENTS}

First and foremost I offer my sincerest gratitude to my major professor, Dr. Cem Karayalcin, who supported me throughout the five years of the Ph.D. program with patience and knowledge. I have learned a lot from him.

I also would like to thank other committee members, Dr. Hakan Yilmazkuday Dr.Alexander McQuoid and Dr.Hassan Zahedi, for their time and valuable suggestions.

Furthermore, I would like to express my gratitude to the faculty in the Department of Economics, for their inspiring teaching and informative lectures. Also, my

wholehearted thanks go to the friendly staff in the department for their prompt and efficient assistance at every stage of my graduate life. 


\section{ABSTRACT OF THE DISSERTATION \\ THREE ESSAYS ON TAXATION, GROWTH AND CONSUMPTION}

by

Yi Ding

Florida International University, 2014

Miami, Florida

Professor Cem Karayalcin, Major Professor

The purpose of this dissertation is to examine three distributional issues in macroeconomics.

First I explore the effects fiscal federalism on economic growth across regions in China. Using the comprehensive official data set of China for 31 regions from 1952 until 1999, I investigate a number of indicators used by the literature to measure federalism and find robust support for only one such measure: the ratio of local total revenue to local tax revenue. Using a difference-in-difference approach and exploiting the two-year gap in the implementation of a tax reform across different regions of China, I also identify a positive relationship between fiscal federalism and regional economic growth.

The second paper hypothesizes that an inequitable distribution of income negatively affects the rule of law in resource-rich economies and provides robust evidence in support of this hypothesis. By investigating a data set that contains 193 countries and using econometric methodologies such as the fixed effects estimator and the generalized method of moments estimator, I find that resource-abundance improves the quality of institutions, as long as income and wealth disparity remains below a certain threshold. When inequality moves beyond this threshold, the positive effects of the resource-abundance level on institutions diminish quickly and turn negative eventually. This paper, thus, provides robust evidence about the endogeneity of 
institutions and the role income and wealth inequality plays in the determination of long-run growth rates.

The third paper sets up a dynamic general equilibrium model with heterogeneous agents to investigate the causal channels which run from a concern for international status to long-run economic growth. The simulation results show that the initial distribution of income and wealth play an important role in whether agents gain or lose from globalization. 


\section{TABLE OF CONTENTS}

CHAPTER

PAGE

1. THE EFFECTS OF FEDERALISM ON ECONOMIC GROWTH IN CHINA

IN $1990 \mathrm{~S} \ldots \ldots \ldots \ldots \ldots \ldots \ldots \ldots \ldots$

1.1 Introduction . . . . . . . . . . . . . . . . . . 1

1.2 China's Tax Reform of $1994 \ldots \ldots$. . . . . . . . . . . . . 3

1.2.1 The Fiscal System from 1979 to 1993: Baogan System . . . . . . . . . 4

1.2.2 The Fiscal System since 1994: Fen Shui Zhi . . . . . . . . . . . 5

1.3 Empirical Analysis . . . . . . . . . . . . . . . . . . . 7

1.3.1 Data Overview . . . . . . . . . . . . . . . . . . . . . . 8

1.3.2 The Fixed Effects Model Approach: Before and After 1994 . . . . . . . 9

1.3.3 Difference-in-Difference Analysis: A Quasi-Natural Experiment . . . . 13

1.4 Conclusion and Remarks . . . . . . . . . . . . . . . . . . . . . 15

2. THE ECONOMIC ORIGIN OF THE RULE OF LAW . . . . . . . . . 23

2.1 Introduction . . . . . . . . . . . . . . . . . . . . . 23

2.2 Data . . . . . . . . . . . . . . . . . . . . . . 25

2.2 .1 The Standardized Income Gini _ . . . . . . . . . . . . . . . . 25

2.2 .2 The Rule of Law . . . . . . . . . . . . . . . . . . . . . 27

2.2 .3 Measuring the Education Inequality _ . . . . . . . . . . . . . . 29

2.2 .4 The Resources Indicators . . . . . . . . . . . . . . . . . . . . . 30

2.3 Empirical Analysis . . . . . . . . . . . . . . . . . . . . . 31

2.3 .1 The Static Model . . . . . . . . . . . . . . . . . . . . . . . . . 31

2.3.2 The Dynamic Panel Results . . . . . . . . . . . . . . . . . . . . . 37

2.4 Conclusion . . . . . . . . . . . . . . . . . . . . . . . . . . . 40

3. NOTES ON GLOBALIZATION, GROWTH, AND RELATIVE CONSUMP-

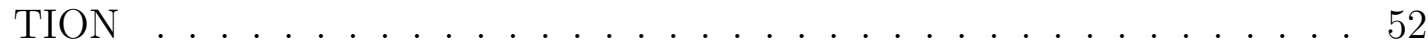

3.1 Introduction . . . . . . . . . . . . . . . . . . . . 52

3.2 Autarkic Equilibrium . . . . . . . . . . . . . . . . . . . 55

3.3 Global Equilibrium . . . . . . . . . . . . . . . . . . . . . . 60

3.3.1 Comparison group: Global average . . . . . . . . . . . . . . 61

3.3.2 Comparison group: Domestic rich vs foreign rich . . . . . . . . . . 62

3.4 Conclusion . . . . . . . . . . . . . . . . . . . . . 67

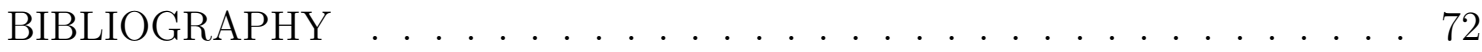

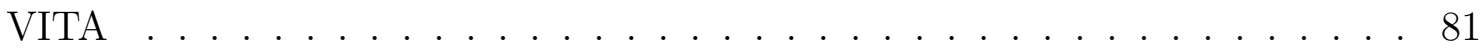




\section{LIST OF TABLES}

TABLE

PAGE

1.1 Descriptive Statistics of All Regions of China 1980-1999 . . . . . . . . . 17

1.2 Fixed Effects Model with Entire Data Set 1980-1999 (1) . . . . . . . . . 17

1.3 Fixed Effects Model with Entire Data Set 1980-1999 (2) . . . . . . . . . 18

1.4 Fixed Effects Model with Entire Data Set 1980-1999 (3) . . . . . . . . . 18

1.5 Fixed Effects Model Before and After $1994(1)$. . . . . . . . . . . . . . 18

1.6 Fixed Effects Model Before and After $1994(2)$. . . . . . . . . . . . . 19

1.7 Regression Results with Difference-in-Difference . . . . . . . . . . . . . 19

2.1 Correlation Between Rule of Law from WGI and ICRG . . . . . . . . . 41

2.2 Existing Individual Effects in WGI Data Set . . . . . . . . . . . . . 42

2.3 Existing Individual Effects in ICRG Data Set . . . . . . . . . . . 43

2.4 Random Effects Model Results . . . . . . . . . . . . . . . . . 44

2.5 DPD estimator for ICRG data set (Oil) . . . . . . . . . . . . . 44

2.6 DPD estimator for ICRG data set (Gold) . . . . . . . . . . . . . 45 


\section{LIST OF FIGURES}

FIGURE

PAGE

1.1 Local Revenue and Expenditure Share 1979-2010 . . . . . . . . . . . . . 20

1.2 GDP Growth Heterogeneity across Provinces in China 1980-1999 . . . . 20

1.3 GDP Growth Heterogeneity across Years in China 1980-1999 . . . . . . 21

1.4 Education Share Heterogeneity Across Provinces 1980-1999 . . . . . . . 21

1.5 Openness Heterogeneity Across Provinces 1980-1999 . . . . . . . . . . . 22

2.1 Gini(Disposable Income) Heterogeneity across Countries . . . . . . . . 46

2.2 Similarity Between Rule of Law from WGI and ICRG . . . . . . . . . . 47

2.3 The Heterogeneity of Rule of Law Across All Countries (WGI) . . . . . 48

2.4 The Heterogeneity of Rule of Law Across All Countries (ICRG) . . . 49

2.5 The Heterogeneity of the Rule of Law Across Periods (WGI) . . . . . . 50

2.6 The Heterogeneity of the Rule of Law Across Periods (ICRG) . . . . . 51

3.1 Simulated Results Consumption Time Path . . . . . . . . . . . . . . 69

3.2 Simulated Results $\phi$ Time Path . . . . . . . . . . . . . 70

3.3 Simulated Results of Time paths of $f$ and $\gamma \ldots \ldots$. . . . . . . 71 


\section{LIST OF ACRONYMS}

Difference-in-Difference DID

Dynamic Panel Data set DPD

Gross Domestic Product $\quad$ GDP

Generalized Method of Moments $\quad$ GMM

International Country Risk Guide ICRG

Luxembourg Income Study $\quad$ LIS

$\begin{array}{ll}\text { Ordinary Least Square } & \text { OLS }\end{array}$

Standardized World Income Inequality Database SWIID

Worldwide Governance Indicators $\quad$ WGI

World Income Inequality Database $\quad$ WIID 


\section{CHAPTER 1 \\ THE EFFECTS OF FEDERALISM ON ECONOMIC GROWTH IN CHINA IN 1990S}

\section{$1.1 \quad$ Introduction}

The effects of fiscal decentralization for economic outcomes have been widely discussed in theoretical work, suggesting that such decentralization improves the efficiency of the use of resources for two main reasons. First, local governments are believed to be better informed about local preferences. Second, as decentralization promotes inter-jurisdictional competition, mobile factors such as capital and labor are expected to move to those jurisdictions that offer better rates of return through the provision of local public goods and advantageous tax rates (See Oates (1972), Tiebout (1956)). However, these channels may not work as expected. Although local governments may know better about local preferences, certain organizational settings are still necessary to prevent local governments from eliminating either the positive or negative market incentives (See Qian \& Weingast (1997)). Most importantly, for local politicians to adopt efficient policies in a decentralized setting, political institutions need to provide the right incentives to ensure the accountability of local governments. In the absence of such accountability, it is often observed (Russia is a prominent example in the literature, for instance) that local governments are captured by special interest groups with the result that decentralization is accompanied by corruption and negative economic outcomes. Thus whether centralization or decentralization would promote political and economic outcomes fostering better government quality, economic growth, and efficient provision of public goods remains an empirical question. Existing empirical studies of the question so far have 
remained inconclusive, their results depending on the countries in the sample, the time frame covered, and the fiscal centralization/decentralization indicators chosen.

In the present paper, I provide a new perspective on the question of fiscal federalism, focusing on China. The use of Chinese data is especially instructive in this regard as China, like several other emerging economies, had in the 1980s adopted an explicit policy of fiscal decentralization (see Taillant (1994), Martinez-Vazquez \& McNab (2003)). That policy had been unchanged until 1992. China has also maintained an average annual growth rate of 10 percent since 1979. Montinola et al. (1995) attributes the rapid and steady growth to the adoption of a fiscal system characterized as federalism ${ }^{1}$, Chinese style, which has preserved and promoted markets and political durability and served as a commitment device to guarantee the economic gains offered by federalism. Blanchard \& Shleifer (2001) suggests that political centralization was crucial in the success of Chinese federalism in this period.

However, existing empirical studies have not necessarily supported the thesis that fiscal decentralization has promoted growth in China. For example, Zhang \& Zou (1998) finds a negative and robust effect of fiscal decentralization on the China's provincial economic growth from 1986 to 1992, while Lin \& Liu (2000) provides evidence of positive and significant effects with "production-based-function regression analysis" using provincial data from 1970 to 1993. Such contradictory results on the question of fiscal federalism are not peculiar to China. The literature on the subject is replete with empirical studies that employ different data sets for different countries reporting contradictory results. For instance, Xie et al. (1999) examined the United States spending data on three levels, and found that the distribution of current fiscal expenditure is optimum and that further fiscal decentralization might

\footnotetext{
${ }^{1}$ In this paper, the term federalism and the term fiscal decentralization are used interchangeably, although the former covers more than the latter.
} 
harm the economy. Thiessen (2000) finds a positive relation between economic growth and fiscal federalism using a sample that includes western developed countries, certain middle-income countries, and some developing economies with a large land size (Martinez-Vazquez \& McNab (2003)).

In this paper, I provide new evidence on the effects of fiscal federalism in China by using a data set that has not been used before in the literature and focus on a quasi-natural experiment that took place in 1992 to study the effects of a dramatic tax reform that redefined the fiscal role of the central government vis-a-vis the subnational governments. In doing this, I argue that two groups of indicators, which measure the degree of fiscal decentralization from both the expenditure and the revenue side, should be adopted.

The rest of the paper is organized as follows. Section 1.2 provides an introduction to China's tax reform in 1994 from the perspective of fiscal relations between the central government and local governments. Section 1.3 starts by describing the data set used to analyze the effects of the tax reform on China's economic growth; section 1.3.2 uses fixed effects models with different time frames, while section 1.3.3 takes the difference-in-difference approach to test the effects of change in tax policy on growth. The last section concludes the paper.

\subsection{China's Tax Reform of 1994}

The year 1979 was a key period in terms of China's economic development, when the country officially announced the plan for economic reform, known as reform and opening-up. Fiscal relations between the central government and the local (i.e., subnational) governments evolved in two distinct stages since then (see Dabla-Norris (2005)): decentralized revenue in the 1980s and centralized revenue in the mid-1990s. 


\subsubsection{The Fiscal System from 1979 to 1993: Baogan System}

In the 1980s, China gradually developed a fiscal contract system, under which lowerlevel governments negotiated with upper-level governments regarding the budgetary revenue sharing scheme (Montinola et al. (1995)). Though the details of each contract remained unclear, these contracts can be classified into two forms:

1. A fixed or adjusted quota scheme was established, under which local governments remitted to or received from the central government a fixed amount, subject to upward adjustments.

2. A proportional arrangement was also constructed so that the central government and the local governments shared the budgetary revenue in accordance to a negotiated ratio.

Although there were different types of contracts and local governments could choose among them, the fiscal contract system essentially featured revenue decentralization because the regulatory authority was mainly moved from the central government to local governments and directly related the local revenues to the economic performance of the latter.

The new system was expected to stimulate the regional economic growth by encouraging local governments to "eat from separate kitchens", aligning the interests of local governments and enterprises, thus promoting the adoption of efficient local economic policies by agencies facing hard budget constraints (Qian \& Roland (1999)). It would also prevent the central government from intervening directly in the market and serve as an instrument to preserve both positive and negative market incentives (Qian \& Weingast (1997)).

Results of existing empirical studies, however, do not agree as to whether the expectations were met. Zhang \& Zou (1998) finds "a constant and robust higher 
degree of fiscal decentralization of government spending is associated with lower provincial economic growth" over this period, while Jin et al. (2005) reports results that contradict Zhang \& Zou (1998).

A prominent outcome of the fiscal contract system of the 1980s was the drop in the share of total revenue received by the central government from 39 percent to 22 percent in 1993 (Dabla-Norris (2005), also see Figure 1.1). As a result the fiscal deficit was as large as 12.7 percent of total revenue in 1993(Shu-Ki \& Yuk-Shing (1994)). The decrease in the share of revenue received by the central government was considered to be unsustainable and indicated furthermore that the increase in the bargaining power of local governments would endanger political centralization that was crucial for the success of Chinese style federalism (Blanchard \& Shleifer $(2001))$.

\subsubsection{The Fiscal System since 1994: Fen Shui Zhi}

The central government decision to undertake tax reform was made in 1989 and the reform was implemented in the entire country by mid-1993, with nine regions adopting the new tax system in 1992 and the rest following in 1993. Under the new tax system, taxes were divided into three categories(Shu-Ki \& Yuk-Shing (1994)) ${ }^{2}$ :

1. Central taxes: Tariffs, income taxes on central enterprises, taxes on revenues from railways, banks and insurance companies, income taxes from financial institutions obtaining licenses from People's Bank of China, the central bank, consumption taxes, offshore oil resource taxes;

\footnotetext{
${ }^{2}$ Also see "Finance Vice Minister on Central-Local Tax Assignment", China Economic News, Beijing, Vol.XV, NO.1, 3 January, 1994, pp.7-8.
} 
2. Local taxes: Business taxes (excluding those paid by banks, railways and insurance companies), income taxes from local enterprises, personal income taxes; capital gains taxes on land and property sales, estate duties, stamp duties

3. Shared taxes: Value-added tax, $75 \%$ of which is received by central government, capital gains taxes on stocks, $50 \%$ of which to be received by central government, resources taxes other than the offshore oil resource tax, most of which to be received by local governments.

The main goal of this tax assignment system was to raise the central-to-local tax assignment ratio from 40:60 in 1993 to 60:40 (without a specific time frame for the attainment of this goal). In order to avoid resistance from local governments, the central government also decided to carry out this plan gradually and in a "step by step" manner so that local governments were protected from being deprived of the tax benefits they so far enjoyed. Specifically, in 1993, the central government rebated whatever amount was transferred from local governments because of the tax reform back to them and defined it as the base amount. From then on, the central government increased the rebate amount by $0.3 \%$ every year with each $1 \%$ increase in the sum of two types of tax: consumption tax and value added tax. With the rebate system, the central government kept the promise that under the new tax assignment system local governments would receive revenues no less than those under the old one.

The reform achieved its designated goal as the total revenue collections increased to over $18 \%$ of GDP in 2002 and the central government share of the total budge revenue increased to around 50\% in 2002 (Dabla-Norris (2005)). However, the expenditure scheme did not change much with the tax reform and continued with 
its long-run trend: local governments were responsible for a large portion of total expenditures, especially in education, culture and health areas ${ }^{3}$.

The contrast between the revenue sharing scheme and that of expenditures raises a question central to the empirical studies of fiscal decentralization: the theoretical literature typically supposes that the ratio of the revenue received by the central government to the total revenue and the ratio of central government spending to total spending to move in the same direction as they are assumed to be compatible measures of fiscal federalism. According to the conventional view, a more decentralized country must present smaller values for both ratios. Following this convention, China showed both fiscal centralization and fiscal decentralization after the tax reform in 1994, because the ratio of revenue received by the central government to the total went up while the ratio of expenditures by the central to total expenditures went down simultaneously. In what follows I will be concerned about the implications of these changes in interpreting the effects of the Chinese tax reform of 1994.

\subsection{Empirical Analysis}

This section presents two ways of analizing the effects of the 1994 tax reform on the growth of China. Section 1.3.2 adopts a fixed effects model to determine the sign and the significance of the effects of fiscal reform, controlling for other relevant economic variables. Section 1.3.3 focuses on regional growth two years before and after the policy change using a Difference-in-Difference methodology.

\footnotetext{
${ }^{3}$ The difference between the expenditures of local governments and their budgetary revenue was compensated by increasing transfers from the central government.
} 


\subsubsection{Data Overview}

The regional data I use covers all 31 provinces of mainland China between 1980 and 1999, including data on revenues, expenditures, GDP, population and other economic variables of interest ${ }^{4}$. However, a few provinces were dropped from the sample because of data unavailability. For example, Tibet was dropped in the fixed effects model in section 1.3.2 because of missing growth rates. Table 1.1 presents descriptive statistics of the variables used at the provincial level: the number of observations, the mean, the standard deviation, and the minimum and the maximum values.

The data set used in section 1.3.2 and section 1.3.3 are both derived from the data in Statistical Data and Materials on 50 Years of New China. As pointed out earlier, the existing empirical literature obtains contradictory results concerning the effects of the fiscal decentralization. In an attempt to resolve the question, I employ a two-pronged strategy to exploit the regional data set from Department of Comprehensive Statistics (1999). The first strategy takes the form of examining the entire time period from 1980 through 1999 and the second analyzes the two periods before and after 1994 separately.

\footnotetext{
${ }^{4}$ Source: Department of Comprehensive Statistics (1999).
} 


\subsubsection{The Fixed Effects Model Approach: Before and After 1994}

Because of the heterogeneity across provinces ${ }^{5}$, I first adopt the fixed-effects model to analyze provincial economic performance from 1980 through 1999 and focus on the average within-unit effects of fiscal reform on regional growth ${ }^{6}$.

The specific fixed-effects model I employ takes the following form,

$$
\Delta Y_{i, t}=\alpha_{i}+\beta_{0} d_{i, t}+X_{i, t} \beta_{1}+u_{i, t}
$$

where $\Delta Y_{i, t}$ is the GDP growth, $d_{i, t}$ represents different choices of fiscal decentralization indicators, $X_{i, t}$ is the vector of variables that help explain heterogeneity across provinces but may be time variant. $\alpha_{i}$ captures fixed effects for each province.

In the empirical analysis, two provinces, including Hainan and Tibet, were dropped from the data set because GDP growth data were unavailable for them. Chongqing was a city affiliated with the Sichuan province and had not been directly supervised by the central government until 1997, when it became one of the four municipalities. ${ }^{8}$ Thus, both Chongqing and Sichuan were dropped from the data set.

\footnotetext{
${ }^{5}$ See Figure 1.2.

${ }^{6}$ The estimators for slopes in the fixed effects model might be thought of as the average within-unit effects of corresponding explanatory variables on the dependent variable. I have also compared the heterogeneity across provinces with that across time and found that the latter is trivial ${ }^{7}$.

${ }^{8}$ In mainland China, there are three different names equivalent to each other in terms of administrative level: the province, the municipality and the autonomous region. The counterpart in the U.S. is the state. There are 23 provinces, 5 autonomous regions and 4 municipalities in China now.
} 


\section{The Fixed Effects Model 1980-1999}

The first set of regressions focuses on the entire sample and the results are reported in table 1.2 ,table 1.3 and table 1.4

The conventional indicators used in the literature were not adopted because, as mentioned earlier, they move in opposite directions after the tax reform in 1994. Instead, I take both expenditures and revenues into consideration to better measure the degree of fiscal decentralization. The first six models reported in the table differ in terms of the indicators of fiscal decentralization. The qualitative conclusion is that, as expected, fiscal decentralization is positively correlated with regional economic growth. These correlations are robust to the inclusion of economic control variables.

One result worthy of note in table 1.2 is that two indicators, the ratio of local expenditure to local total revenue and the ratio of local total revenue to local tax revenue, have significant positive and negative effects respectively. These estimates remain significant in both table 1.3 and table 1.4. At first sight, it may be surprising to see that increases in local revenue would slow down economic growth, as suggested by the signs of these two significant indicators. It is, therefore, important to note that local revenues in the data come from two sources, namely local tax revenue and transfers from the central government. These transfers are typically earmarked

for specific uses and do not represent fiscal decentralization. For a given level of transfers from the central to the local government, increases in local tax revenues and in local spending, both representing a higher degree of fiscal decentralization, are positively correlated with economic growth.

Given the significance of these two indicators, I reestimate the model including additional control variables that may help explain economic growth. These control variables are education expenditure as a share of GDP, the population growth rate, 
and the degree of openness. The estimated coefficient of degree of openness is not significant in any regression, while that of education spending is significant (and negative) only when population growth is excluded. However, as suggested by figures 1.4 and 1.5 , these observations may reflect the heterogeneity across provinces lasting for the entire time horizon, which should be captured by a time-invariant dummy variable.

\section{The Fixed Effects Model: Before and After 1994}

Given the significance of the fiscal indicators in the model using the regional data set from 1980 to 1999, I next investigate their behavior in the two periods before and after the fiscal reform in 1994. The estimation results are reported in table 1.5 and table 1.6.

I have four basic conclusions from the regression results,

1. Neither the ratio of local expenditure to local total tax revenue nor the ratio of local total revenue to local expenditure explains GDP growth well regardless of the period;

2. The ratio of local expenditure to local total revenue, which is always significant in the sample 1980 to 1999, becomes insignificant after 1994;

3. Both the ratio of local tax revenue to local total revenue and the ratio of local tax revenue to local expenditure become significant after 1994, although they ere not significant in the previous period;

4. The ratio of total local revenue to local tax revenue preserves its sign and significance, with the estimated absolute value of the coefficient rising significantly. 
These results are best explained with recourse to the specifics of the 1994 tax reform in terms of its effects on the distribution of revenues. Before 1994, most of local spending was financed by revenues raised by local governments, with the central government remitting smaller amounts subject to negotiations between individual local governments and the central government. As the central government only received a portion of the total (tax) revenue, the transfers from central to local governments were relatively smaller compared to the post-1994 period. In other words, the local governments raised taxes, transferred a portion to the central government and were allowed to exercise discretion in spending the rest. Thus, indicators about local expenditures before 1994 represented the actual degree of fiscal decentralization more accurately than indicators of local revenue. After 1994, the central government successfully increased its share of the country's total tax revenue from roughly $40 \%$ to $60 \%$. At the same time, because extra local spending became subject to a request and approval process from the central government as discussed in section 1.2 , the indicators on the expenditure side do not accurately reflect the degree of fiscal decentralization. Furthermore, the revenue side has become a better indicator of fiscal decentralization as provinces with higher (tax) revenue have been able to keep an increasing share of their revenues and get higher rebates from the central government according to the uniform tax distribution scheme adopted after $1994 .^{9}$

To sum up, the results so far suggest that fiscal decentralization is positively correlated with regional GDP growth. The multiplicity of the dimensions of fiscal decentralization do raise some problems with regard to the choice of decentralization

\footnotetext{
${ }^{9}$ This solely refers the rebate system adopted with the 1994 tax reform and does not include the additional transfers from the central government, which are usually earmarked.
} 
indicators but, as it showed, a closer look at the institutional structures helps clear the conceptual difficulties.

\subsubsection{Difference-in-Difference Analysis: A Quasi-Natural Experiment}

As mentioned in the introduction to the Chinese tax reform of 1994, the reform was carried out in two stages: the country was divided into two groups, one, denoted as Group A, implemented the reform in 1992, the other, denoted as Group B, followed in 1994. This two-stage reform process gives a quasi-natural experiment setup and provides me with the opportunity to apply difference-in-difference techniques, which require both an treatment and a control group.

Specifically, in 1992, the central government decided to test the new tax assignment system initially (Shu-Ki \& Yuk-Shing (1994)) ${ }^{10}$ in nine regions, including Zhejiang Province, Liaoning Province, Xinjiang Autonomous region, Tianjin municipality, Shenyang City, Daian City, Qingdao City, Wuhan City, and Chongqing City. Both Shenyang and Dalian belongs to Liaoning Province, Qingdao belongs to Shandong Province, Wuhan belongs to Hubei Province and Chongqing was a city affiliated to Sichuan Province until 1997. As the data set is at the province level, I include Zhejiang, Liaoning, Xinjiang and Tianjin in group A, and moved Shandong, Hubei, Sichuan and Chongqing to group B. Again, because of data unavailability, Hainan and Tibet were dropped.

\section{Difference-in-Difference Estimation Results}

The regression equation takes the standard difference-in-difference form,

\footnotetext{
${ }^{10}$ Also see "Finance Vice Minister on Central-Local Tax Assignment", China Economic News, Beijing, Vol.XV, no.1 (3 January 1994), pp.7-8.
} 


$$
\Delta y_{i, t}=\alpha+\beta_{0} Z_{i . t}+\beta_{1} T_{i}+\beta_{2} P_{i}+\gamma T_{i} * P_{t}+\epsilon_{i, t}
$$

where $\Delta y_{i, t}$ represents either the regional GDP growth or the regional per capita GDP growth rate (I use these two GDP growth rates to test the robustness of the estimator). The variable $Z_{i . t}$ is a control variable indicating the initial value of either GDP or per capita GDP. The dummy variable, $T_{i}$, is for whether the province is in the treatment group, i.e. Group A, taking the value of one if the corresponding province is in the treatment group and zero otherwise. Another dummy variable, $P_{i}$, indicates whether the observation is made after 1991, with the value of one if the corresponding observations is made after 1991 and zero otherwise. The $\gamma$ is the coefficient for the interaction term, the product of $T_{i}$ and $P_{t}$, and captures the treatment effects, namely the difference between the change in the treatment group and that in the control group due to the tax reform. The estimation results are reported in table 1.7,

Model (26) and model (27) take the provincial total GDP growth as the dependent variable, while models (28) and (29) take the provincial per capita GDP as the dependent variable. It is only in the model (28) that the interaction term shows a significant coefficient at $10 \%$ significant level, while the other three regressions do not present significant results for the coefficient of the interaction term. Thus, the results here suggest that the tax reform is associated with "less developed" provinces growing at even slower rates, with model (28) being used to test the treatment effects in the lower $75 \%$ per GDP growth group.

Given what I found in the section 1.3.2, where the fixed effects models showed changes in the significance of different fiscal decentralization indicators with different time periods, I can interpret the results in table 1.7 in the following way. As I discussed earlier on page 10, given the central government promise that local 
governments do not experience reductions in their revenues (a promise backed up by increases in transfers to local governments) richer provinces tend to get larger transfers from the central government. Within the short time period of 2 years after the tax reform, those relatively poor provinces with lower growth rates faced the situation where they had to remit the same percentage of revenue as others but received smaller transfers compared to the richer provinces, thus, had their growth rates slow further down.

The difference-in-difference setting adopted here has certain shortcomings because of data limitations that need to be identified.

1. The effects of the tax reform on regional economic growth may not be picked up in the data within only two years. A data set covering a longer time horizon would be more useful in examining the differences between the treatment group and the control group. As the control group was subjected to the same reform relatively quickly after the treatment group, my analysis was limited to a short time horizon and the results might reflect this.

2. There are only 4 provinces in the treatment group, while there are 21 provinces in the control group. The small size of the treatment group would bias the estimators. For example, Donald \& Lang (2007a) suggests that if the size of the group is not large enough, the error term is not homoscedastic.

\subsection{Conclusion and Remarks}

In this paper, I took China's 1994 tax reform as an example of a change in the level of fiscal decentralization and examined its effects on regional economic growth. I found the conventional fiscal decentralization indicators, including the ratio of local revenue to the national revenue and the ratio of local expenditure to the national 
expenditure, to be deficient for the purposes as they are not consistent with each other: one increased while the other decreased for the same country (i.e., China) during the same period (i.e., 1994-1999). In other words, the multiple dimensions of fiscal decentralization implied that none of the one-sided indicators works well as a measure of the degree of fiscal decentralization. I then turned to another set of indicators incorporating the revenue side and the expenditure side together. To test their robustness, I applied these indicators to three samples: 1980-1999 period taken as a whole, 1980-1994 and 1994-1999 periods taken separately. The estimation results suggest that the significance of any given indicator varies with the time period for reasons to do with the specifics of the tax reform. Moreover, I did find the ratio of local total revenue to tax revenue to be robust in all the regressions.

Next I used the incremental nature of the tax reform as a quasi-natural experiment and used a difference-in-difference estimation procedure. Here, estimation results are only significant for the "less developed" provinces. It might be a reflection of the sample selection process associated with the quasi-natural experiment and the results could be improved if time frame was extended and sample size was increased. As the nature of the experiment only provides for a two-year window, it is hard to further improve the estimation results within this specific analysis. 
Table 1.1: Descriptive Statistics of All Regions of China 1980-1999

\begin{tabular}{lccccc}
\hline Variable & Obs & Mean & Std. Dev. & Minimum & Maximum \\
\hline year & N/A & N/A & N/A & 1980 & 1999 \\
GDP & 1309 & 876.6836 & 1114.779 & 81.7 & 10375.6 \\
Local Revenue & 1403 & 41.18031 & 65.85449 & -1.1021 & 766.19 \\
Taxes & 1302 & 33.32606 & 54.96021 & .0302 & 507.13 \\
Industrial \& Commercial Taxes & 1182 & 28.26344 & 50.80506 & .0279 & 497.54 \\
Local Expenditure & 1403 & 45.68509 & 86.53568 & .05 & 965.9 \\
Capital Construction cost & 1314 & 5.988916 & 10.42732 & .01 & 143.86 \\
Education,Culture, Sciences and Health & 1387 & 11.46312 & 22.82099 & .03 & 244.18 \\
Government Administrative & 1350 & 5.023328 & 8.736905 & .08 & 74.05 \\
Population & 1381 & 2827.861 & 2049.529 & 122.8 & 9387 \\
Imports and Exports & 1083 & 223020 & 1012428 & 5.51 & 14000000 \\
\hline
\end{tabular}

Note:The GDP of 1952 was taken as the base year and all the other years were taken as the percentage of it. All the numbers of revenue and expenditure are in hundreds of millions yuan. The population is in tens of thousands.

Table 1.2: Fixed Effects Model with Entire Data Set 1980-1999 (1)

\begin{tabular}{lccc}
\hline & $(1)$ & $(2)$ & $(3)$ \\
\hline local total revenue to expenditure & $-0.007^{* *}$ & & \\
local tax revenue to expenditure & $(0.003)$ & & \\
& & $-0.01^{*}$ & \\
local total revenue to tax revenue & & & $-0.006)$ \\
& & & $(0.009)$ \\
\hline Prob $>\mathrm{F}$ & 0.018 & 0.085 & 0.004 \\
\hline
\end{tabular}

Note: superscripts $*,{ }^{* *}$ and ${ }^{* * *}$ denotes significance at $10 \%, 5 \%$ and $1 \%$ respectively. Standard errors are in parenthesis. 
Table 1.3: Fixed Effects Model with Entire Data Set 1980-1999 (2)

\begin{tabular}{lccccc}
\hline & $(4)$ & $(5)$ & $(6)$ & $(7)$ & $(8)$ \\
\hline local expenditure to total revenue & $.015^{* * *}$ & $.009^{*}$ & $.010^{* *}$ & $.010^{* *}$ & $.012^{* *}$ \\
& $(0.005)$ & $(0.005)$ & $(0.005)$ & $(0.005)$ & $(0.005)$ \\
Edu,Health,Sci \& Culture & $-.632^{* *}$ & & -.243 & -.264 & \\
& $(0.312)$ & & $(0.314)$ & $(0.331)$ & \\
Population growth & & $-1.965^{* * *}$ & $-1.904^{* * *}$ & $-1.948^{* * *}$ & \\
& & $(0.345)$ & $(0.354)$ & $(0.357)$ & \\
Openness & & & & .012 & .020 \\
& & & & $(0.016)$ & $(0.015)$ \\
\hline Prob $>\mathrm{F}$ & 0.003 & 0.000 & 0.000 & 0.000 & 0.006 \\
\hline
\end{tabular}

The expenditure on education, health, science and culture is measured as the percentage of GDP. The openness is measured by the ratio of total imports and exports to GDP.

Note: superscripts $*, * *$ and $* * *$ denotes significance at $10 \%, 5 \%$ and $1 \%$ respectively.

Standard errors are in parenthesis.

Table 1.4: Fixed Effects Model with Entire Data Set 1980-1999 (3)

\begin{tabular}{lccccc}
\hline & $(9)$ & $(10)$ & $(11)$ & $(12)$ & $(13)$ \\
\hline local total revenue to tax revenue & $-0.026^{* * *}$ & $-0.022^{* * *}$ & $-0.0236^{* * *}$ & $-0.0217^{* * *}$ & $-0.020^{* *}$ \\
& $(0.008)$ & $(0.008)$ & $(0.008)$ & $(0.008)$ & $(0.008)$ \\
Edu,Health,Sci \& Culture & $-0.736^{* *}$ & & -0.357 & -0.343 & \\
& $(0.318)$ & & $(0.317)$ & $(0.331)$ & \\
Population growth & & $-2.108^{* * *}$ & $-2.031^{* * *}$ & $-2.058^{* * *}$ & \\
& & $(0.341)$ & $(0.347)$ & $(0.351)$ & \\
Openness & & & & 0.013 & 0.024 \\
& & & & $(0.016)$ & $(0.016)$ \\
\hline Prob $>\mathrm{F}$ & 0.001 & 0.000 & 0.000 & 0.000 & 0.007
\end{tabular}

Note: superscripts $*, * *$ and $* * *$ denotes significance at $10 \%, 5 \%$ and $1 \%$ respectively.

Standard errors are in parenthesis.

Table 1.5: Fixed Effects Model Before and After 1994 (1)

\begin{tabular}{|c|c|c|c|c|c|c|}
\hline & \multicolumn{3}{|c|}{ Before 1994} & \multicolumn{3}{|c|}{ After 1994} \\
\hline & (14) & $(15)$ & $(16)$ & (17) & (18) & (19) \\
\hline local expenditure to total revenue & $\begin{array}{c}0.016^{* *} \\
(0.006)\end{array}$ & & & $\begin{array}{c}0.026 \\
(0.019)\end{array}$ & & \\
\hline local expenditure to tax revenue & & $\begin{array}{l}0.014^{*} \\
(0.007)\end{array}$ & & & $\begin{array}{c}-0.025^{*} \\
(0.014)\end{array}$ & \\
\hline local tax revenue to total revenue & & & $\begin{array}{c}0.019 \\
(0.014) \\
\end{array}$ & & & $\begin{array}{c}0.132^{* * * *} \\
(0.037) \\
\end{array}$ \\
\hline Prob $>F$ & 0.011 & 0.0520 & 0.190 & 0.170 & 0.073 & 0.0005 \\
\hline
\end{tabular}

Note: superscripts $*,{ }^{* *}$ and ${ }^{* * *}$ denotes significance at $10 \%, 5 \%$ and $1 \%$ respectively.

Standard errors are in parenthesis. 
Table 1.6: Fixed Effects Model Before and After 1994 (2)

\begin{tabular}{|c|c|c|c|c|c|c|}
\hline & \multicolumn{3}{|c|}{ Before 1994} & \multicolumn{3}{|c|}{ After 1994} \\
\hline & $(20)$ & $(21)$ & $(22)$ & $(23)$ & $(24)$ & $(25)$ \\
\hline local total revenue to expenditure & $\begin{array}{l}-0.006 \\
(0.004)\end{array}$ & & & $\begin{array}{c}0.007 \\
(0.026)\end{array}$ & & \\
\hline local tax revenue to expenditure & & $\begin{array}{l}-0.007 \\
(0.009)\end{array}$ & & & $\begin{array}{c}0.069^{* *} \\
(0.031)\end{array}$ & \\
\hline local total revenue to tax revenue & & & $\begin{array}{c}-0.021^{* *} \\
(0.009)\end{array}$ & & & $\begin{array}{c}-0.148^{* * *} \\
(0.031)\end{array}$ \\
\hline Prob $>\mathrm{F}$ & 0.119 & 0.384 & 0.020 & 0.796 & 0.030 & 0.000 \\
\hline
\end{tabular}

Note: superscripts $*, * *$ and $* * *$ denotes significance at $10 \%, 5 \%$ and $1 \%$ respectively.

Standard errors are in parenthesis.

Table 1.7: Regression Results with Difference-in-Difference

\begin{tabular}{rcccc}
\hline & $(26)$ & $(27)$ & $(28)$ & $(29)$ \\
\hline Intercept & $0.085^{* * *}$ & $0.127^{* *}$ & $0.062^{* * *}$ & $0.091^{* *}$ \\
& $(0.014)$ & $(0.043)$ & $(0.007)$ & $(0.032)$ \\
Treatment & 0.048 & -0.006 & $0.056^{* *}$ & -0.045 \\
& $(1.10)$ & $(0.09)$ & $(0.023)$ & $(0.050)$ \\
Period & $0.127^{* * *}$ & $0.172^{* * *}$ & $0.071^{* * *}$ & 0.067 \\
& $(0.020)$ & $(0.053)$ & $(0.011)$ & $(0.040)$ \\
Interaction Term When: & & & & \\
Initial position below 75\% percentile & -0.061 & & $-0.073^{*}$ & \\
Initial position above 75\% percentile & $(0.061)$ & & $(0.040)$ & \\
& & 0.008 & & 0.041 \\
Prob > F & 0.000 & 0.0187 & 0.000 & 0.115
\end{tabular}

Note: superscripts * $* *$ and ${ }^{* * *}$ denotes significance at $10 \%, 5 \%$ and $1 \%$ respectively.

Standard errors are in parenthesis. 
Figure 1.1: Local Revenue and Expenditure Share 1979-2010

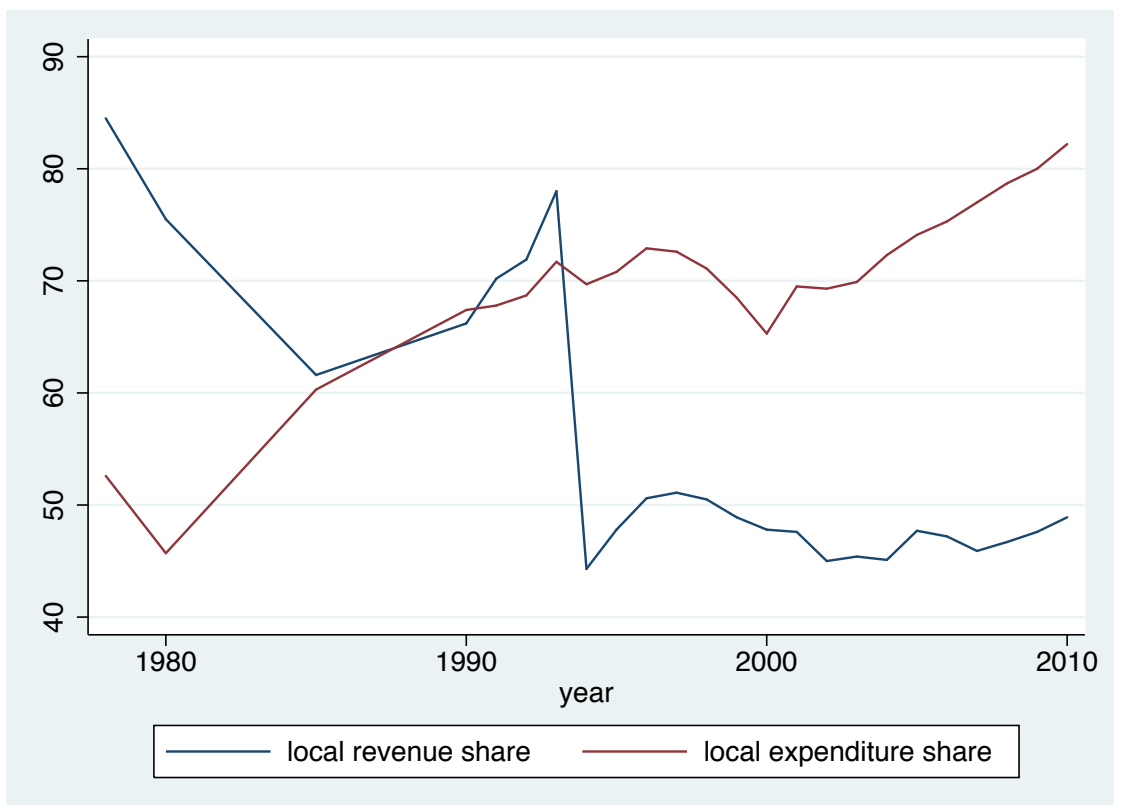

Note: The local share of revenue/expenditure is defined as the ratio of local revenue/expenditure to the total revenue/expenditure,i.e., the summation of local revenue/expenditure and the central revenue/expenditure

Figure 1.2: GDP Growth Heterogeneity across Provinces in China 1980-1999

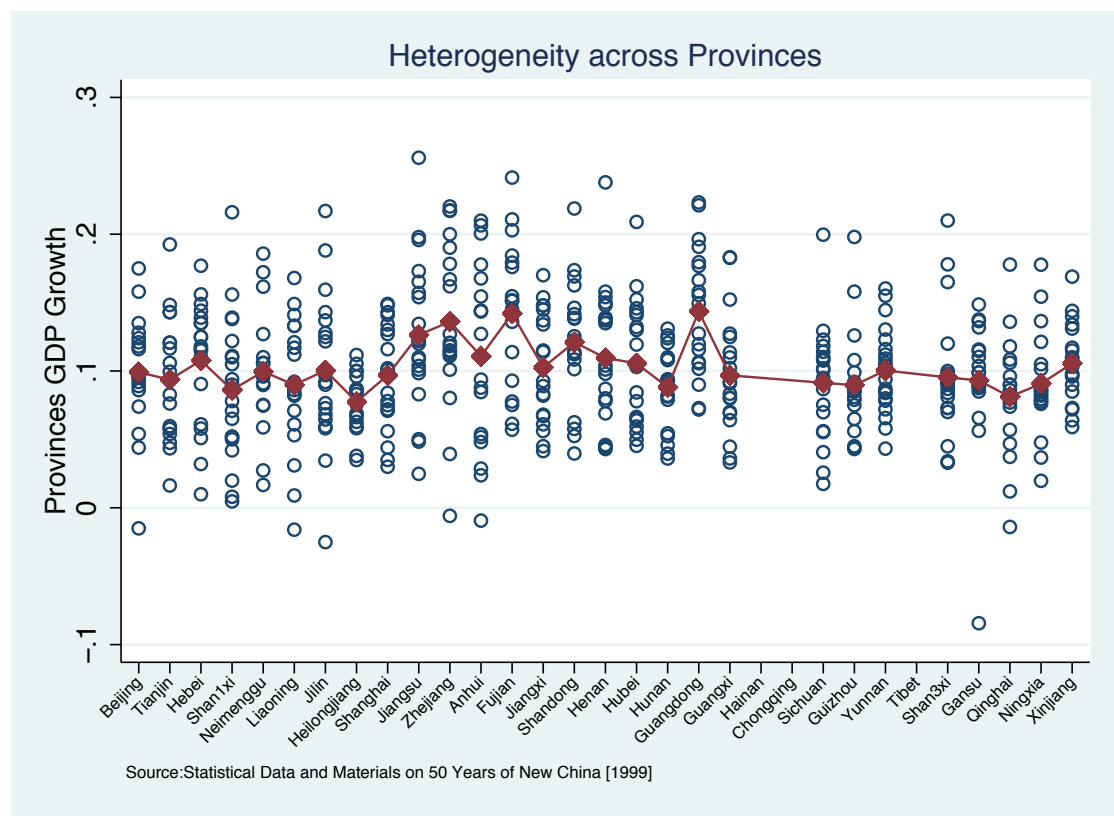


Figure 1.3: GDP Growth Heterogeneity across Years in China 1980-1999

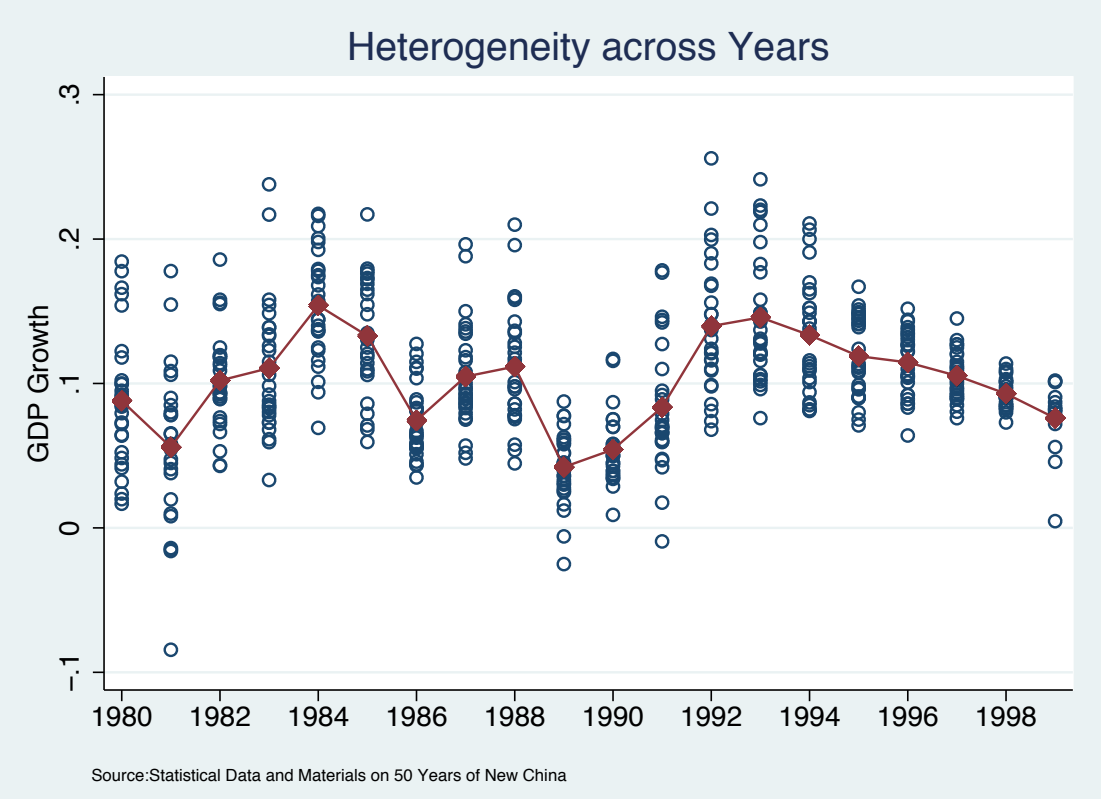

Figure 1.4: Education Share Heterogeneity Across Provinces 1980-1999

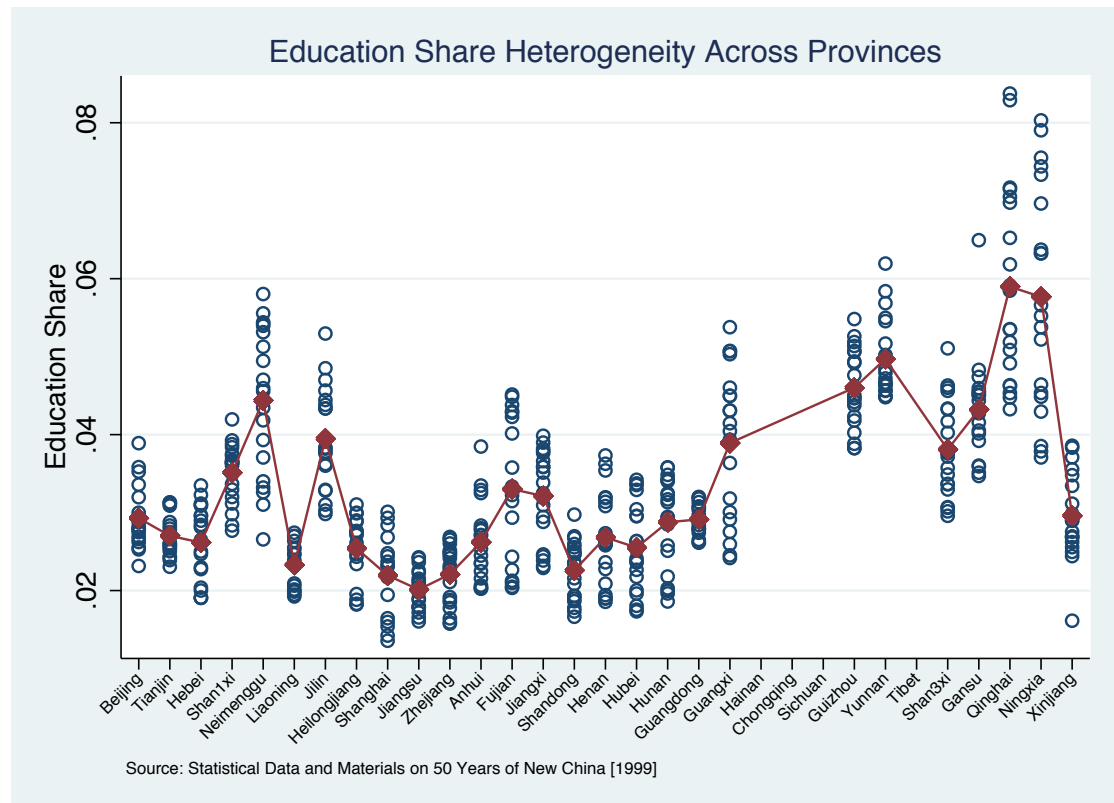


Figure 1.5: Openness Heterogeneity Across Provinces 1980-1999

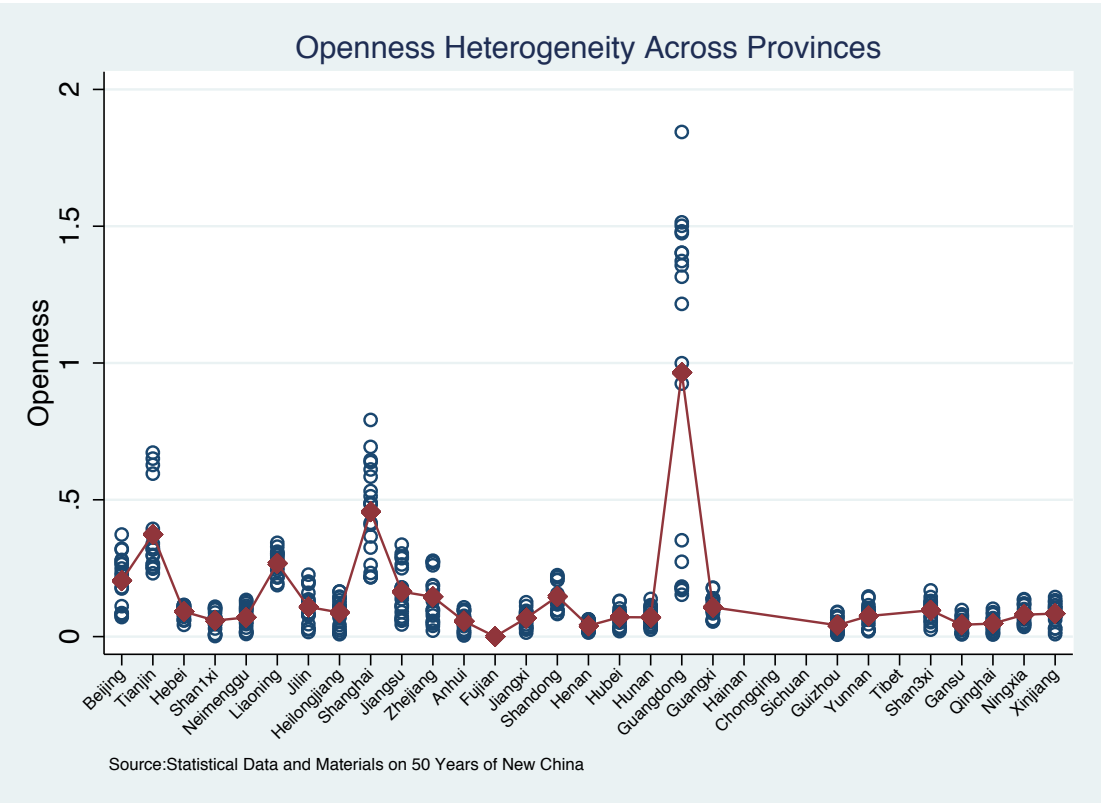




\section{CHAPTER 2}

\section{THE ECONOMIC ORIGIN OF THE RULE OF LAW}

\subsection{Introduction}

The "Resource Curse" found by Sachs \& Warner (1999, 2001) has given rise to an extensive empirical literature that tries to identify the mechanisms underlying the puzzle that countries with abundant resources grow slower than those without them. Leite \& Weidmann (1999), Sala-i Martin \& Subramanian (2003) and Bulte et al. (2005) provide evidence that the effects of resource-abundance on economic growth are marginal after controlling for institutions and price volatility, suggesting that institutions may be the channel via which resource endowments affect economic performance. They also find that the "point resources"-those extracted from a narrow economic or geographic field like oil, mineral or plantation crops (Isham et al. (2005))-are negatively correlated with the quality of institutions. Better institutions, as part of social infrastructure, that provides the background against which agents in an economy interact, accumulate capital, and produce output (Hall \& Jones (1999)), on the other hand, are found to promote economic growth.

The existing literature takes institutions as predetermined and suggests that the effects of resource-abundance largely depends on whether the institutions are "grabber-friendly" or "producer-friendly", i.e., whether resource rents are distributed in favor of rent-seeking activities or production activities (Mehlum et al. (2006)). However, it is easy to see that here a potential endogeneity problem may arise as the precise mechanisms that connects resource-abundance to institutions are still not clear. For example, depending on the level of income inequality, the institution the literature calls the rule of law can be either positively or negatively affected by the discovery of new resources. 
To the extent that property rights are not perfectly and clearly assigned to economic agents, there is an incentive to encroach on the property of others through a variety of means, including legal and extra-legal ones. The more equal a society is in terms of the distribution of its resources, the more level is the playing field in which the contest for additional resources is played out. Consequently, with a more equitable distribution of income and wealth, the incentive to encroach on others property is diminished. As a result, in such societies agents would have stronger incentives to obey the rule of law. As inequality increases, however, the incentives for engaging in a contest to grab the property of others get stronger, with the consequence that the rule of law is less likely to be obeyed and observed. On the other hand, in a society with an unequal distribution of resources, those agents that possess more face increased competition for these resources and, thus, have both an incentive and the means to institutionalize the rule of law. It is, therefore, an empirical question as to whether income and wealth inequality is correlated positively or negatively with the rule of law.

In light of such a conceptual framework, I, therefore, aim to examine whether or not resource-abundance level affects the quality of one specific dimension of institutions, the rule of law as it interacts with income distribution. To the best of my knowledge, the present paper is the first paper that systematically examines this relationship. The same methodology can be easily extended to other dimensions of institutions like democracy or political stability.

The remainder of this chapter is organized as follows: Section 2.2 describes the data set I use in this chapter. Section 2.3 adopts two distinct estimation methodologies and presents the results. Section 2.4 concludes the paper. 


\subsection{Data}

Because both institutional variables and resource indicators change very slowly over time, it is important to understand statistic methodologies that are used to get the data set. Those methodologies also affect my model selection. I reviewed the critical variables that were adopted in the empirical analysis.

\subsubsection{The Standardized Income Gini}

The data set for the income Gini comes from the Standardized World Income Inequality Database (SWIID), which "provides comparable Gini indices of gross and net income inequality for 153 countries for as many years as possible from 1960 to the present along with estimates of uncertainty in these statistics." ${ }^{1}$ There are two popular sources for the income Gini: the Luxembourg Income Study (LIS) and the World Income Inequality Database (UNU/WIDER-UNDP, 2000), known as WIID². However, neither of them is suitable for my worldwide cross-national study. There are two reasons for the lack of of suitability. First, the LIS data set suffers from having a limited number of observations despite having good comparability for crossnational studies ${ }^{3}$. Second, the WIID does not have a consistent variable for income inequality for all countries in its wide coverage ${ }^{4}$ because its observations differ in the definitions of income measured, reference units, population covered and/or sources.

\footnotetext{
${ }^{1}$ Solt, Frederick. 2009. Standardizing the World Income Inequality Database. Social Science Quarterly 90(2):231-242. SWIID Version 3.1, December 2011.

${ }^{2}$ WIID was considered as an update and extension to the data set generated by Deininger and Squire (1996). It assembles more sources and documents them in detail to provide the possibility of generating comparable variables across countries and periods.

${ }^{3}$ LIS only covers up to 36 countries and areas, most of which are among the advanced developed economies, see http://www.lisdatacenter.org/pretechdoc.htm.

${ }^{4}$ Its current version $2.0 \mathrm{C}$ covers 5313 observations.
} 
Although there have been some attempts to improve comparability within the WIID, like Babones \& Rivadulla (2007), their methods rely on adjusting the "secondary data set" (Atkinson \& Brandolini (2001)) by either adding or subtracting constant terms, which may either underestimate or overestimate the real value.

The SWIID constructs the income Gini index across countries and over time in a different way, aiming at maximizing comparability with widest coverage. First, it incorporates both the WIID and the LIS, eliminates the observations that cover only a portion of the population and discards the observations before $1960 .^{5}$ As a result, the new compiled data set covers twenty one categories of income inequality measurements by combining various definitions of income and different reference units. For each country, each year may have up to twenty one observations, where zero means that no observation for any category for that year and twenty one means that the data are available for all the categories. Next, the conversion factor, $\rho_{a b i t}{ }^{6}$ is addressed, i.e., the ratio is directly calculated when the data are available, while it is predicted with models when the data are not available. Then the $\rho_{1 b i t}$, which refers to the ratio of Gini index in LIS net-income data to that in category $b$, is calculated as the product of $\rho_{\text {abit }}$ and $\rho_{1 a i t}$. After all $\rho_{\text {abit }}$ and $\rho_{1 a i t}$ are calculated, twenty series of $\rho_{1 b i t}$ can be obtained and all of them are comparable to LIS netincome data. In other words, there are 20 observations for country $i$ in year $t$ in theory, although almost all the series are incomplete. The next step picks up either one of the observations or their average as the realization of the inequality index

\footnotetext{
${ }^{5}$ The SWIID does not take into consideration the observations for certain groups of people such as urban population, rural residents and so on, because they may not represent the whole country. There are two exceptions, the data for Argentina and Uruguay only covers urban residents as they both exhibit high rate of urbanization $90 \%$ and no observation for the whole population of either country is available.

${ }^{6}$ It is defined as the ratio of Gini index in category $a$ to that in category $b$ for country $i$ in year $t$.
} 
for country $i$ in year $t$, depending on which has the smaller standard error. The final step uses a five-year weighted moving average algorithm to smooth the data. ${ }^{7}$ At the same time, Monte Carlo simulation is adopted to get a point estimate of LIS-comparable net-income inequality and the corresponding standard errors. The complete data set is plotted in figure 2.1.

\subsubsection{The Rule of Law}

The data sets I have for the rule of law variable come from two sources: the Worldwide Governance Indicators (WGI) project and the International Country Risk Guide (ICRG). The former covers more countries with a short time horizon while the latter covers a longer period but a smaller number of countries. However, they are highly correlated with each other and are used in the following econometric estimations to crosscheck the robustness of the econometric results, with one exception: due to the rapid increase in the number of instruments when generalized method of moments (GMM) estimator is applied for the dynamic panel model, WGI is not applicable because of the limited number of observations contained in it.

\section{The Rule of Law from WGI}

The WGI data set, which consists of six indicators regarding the quality of governance based on a large amount of surveys, was updated every two years from 1996 to 2002 and annually since 2002. One of those six indicators is "Rule of Law", "capturing perceptions of the extent to which agents have confidence in and abide by

\footnotetext{
${ }^{7}$ The moving average equation is $G_{i, t}=1 / 6 \times\left(G_{i, t-2}+G_{i, t-1}+2 * G_{i, t}+G_{i, t+1}+G_{i, t+2}\right)$. There are two exceptions: the observations from LIS are not adjusted thanks to its high quality; the observations for eastern Europe and the Soviet Union are not adjusted for the years from 1989 to 1992, because the changes of inequality index values are most likely caused by the social reforms then taking place instead of measurement error.
} 
the rules of society, and in particular the quality of contract enforcement, property rights, the police, and the courts, as well as the likelihood of crime and violence". (Kaufmann et al. (2010)) I used the version released in 2012 in this paper, which covers 215 economies and up to $2011 .^{8}$ The value of the rule of law variable ranges from -2.67 (weak) to 2 (strong) and most of them are between -2 and $1.5 .^{9}$

\section{The Rule of Law from ICRG}

The rule of law from the ICRG data set is one of the twelve indicators for the subcategory "political risk". It consists of two sub-components, namely the "Law" subcomponent and the "Order" sub-component. ${ }^{10}$ The former measures "the strength and impartiality of the legal system" and the latter is "an assessment of popular observance of the law". ${ }^{11}$ Each sub-component is between 0 points (worse) and 3 points (better), thus, the rule of law from ICRG comprises zero to six points. I used the version published at the end of 2010 with 3464 annual observations covering 146 countries from 1984 until 2010. ${ }^{12}$

\footnotetext{
${ }^{8}$ After merging all the data together, I deleted non-independent economies and nonexisting countries as of 2010. I also deleted the observations for 2011 since I focus on the period spanning 1970-2010.

${ }^{9} 2079$ out of 2300 observations fall in the interval.

${ }^{10}$ In the ICRG data set, the name of this variable is "Law and Order".

${ }^{11}$ See http://www.prsgroup.com/.

${ }^{12}$ Similar to the way of dealing with WGI data, I deleted the non-independent economies, non-existing countries as of 2010. I also deleted the observations for 2011 since I am focusing the period spanning 1970-2010.
} 


\section{Correlations between ICRG and WGI}

There are two ways of looking at these numbers as either cardinal or ordinal. They are cardinal numbers because they directly tell the strength of the rule of law for each country in a year; alternatively, they are ordinal numbers since those with lower values in either system have worse rule of law than those with higher values.

To demonstrate the high correlation between these two data sets despite differences in coverage, I first examine the correlation coefficients between the rule of law from WGI and that from ICRG as a whole as well as for each year as shown in table 2.1, where high correlations are present for all the years available in both data sets.

Secondly, I consider the characteristics of these observations as ordinal numbers. While it is difficult to summarize the information when all the observations from both data sets are displayed in one picture, I calculate the mean for the rule of law for each country, using the data from both sources, and then mark these means in figure 2.2 to examine the relative position of each country in both data sets. The visualized statistical results indeed show that the country with a smaller value in one data set also ranks lower in the other.

In conclusion, the high statistical correlation and observed similarity between these two data sets suggest that both measurements for rule of law are plausible.

\subsubsection{Measuring the Education Inequality}

I also introduced the education Gini index as a potential instrument for income inequality. ${ }^{13}$ My basic source of data on education inequality is the well-known

\footnotetext{
${ }^{13}$ Education inequality is highly correlated with economic inequality, see recent work Rodríguez-Pose \& Tselios (2009), Rodríguez-Pose \& Tselios (2010) and Gregorio \& Lee (2002).
} 
Barro-Lee Data set, ${ }^{14}$ which is constructed at 5-year intervals from 1950 to 2010 . In the present paper, these were interpolated into annual series to match the frequency of the other data sources.

I followed the methods introduced in Castelló \& Doménech (2002) to calculate the value of the education Gini. These methods yield the education Gini index value for a country in a given year as:

$$
\text { EduGini }=\frac{1}{2 H} \sum_{i=0}^{i=3} \sum_{j=0}^{j=3}\left|\hat{x}_{i}-\hat{x}_{j}\right| n_{i} n_{j}
$$

where $H$ is the average schooling years of the population aged 15 and over, $n_{i}$ and $n_{j}$ are share of the population with a certain level education, and $\hat{x}_{i}$ and $\hat{x}_{j}$ are the total average schooling years required for attaining each education level. $i, j$ can be any number from 0 to 3 , representing no schooling, primary schooling, secondary schooling and tertiary schooling. Furthermore, equation 2.1 can be expanded as follows:

$$
\text { EduGini }=n_{0}+\frac{n_{1} x_{2}\left(n_{2}+n_{3}\right)+n_{3} x_{3}\left(n_{1}+n_{2}\right)}{n_{1} x_{1}+n_{2}\left(x_{1}+x_{2}\right)+n_{3}\left(x_{1}+x_{2}+x_{3}\right)}
$$

where $x_{i}(i=0,1,2,3)$ is the number of average years for each individual education level.

\subsubsection{The Resources Indicators}

My resource measure is based on the World Bank's The Changing Wealth of Nations data set. ${ }^{15}$ The latest update is published on January 1st, 2010, covering 150 economies. It contains annual estimates of non-renewable resource rent indicators,

\footnotetext{
${ }^{14}$ The version used in calculating the education Gini is v. 1.2, was published in September 2011 .

${ }^{15}$ See http://data.worldbank.org/data-catalog/wealth-of-nations.
} 
including fuel and non-fuel subsoil wealth ${ }^{16}$ as well as forest rent. The arable land from World Development Indicators (WDI) data set was also incorporated into my analysis. For each individual resource, I use log of natural resources per capita.

\subsection{Empirical Analysis}

Below I estimate the effects of natural resource abundance on the rule of law conditional on income inequality. I test both static and dynamic models to exploit two important characteristics of the data set: cross-sectional variation and consistency overtime. I also average all the variables every three years to address two problems of the data set: missing values and the observed small magnitude of variation in the rule of law. Throughout the empirical analysis, I use oil and gold as two different resource indicators, along with two data sets for the rule of law.

\subsubsection{The Static Model}

The static panel model is as follows,

$$
R L_{i, t}=\alpha_{i}+\beta_{1} \operatorname{Gini}_{i, t}+\beta_{2} R S_{i, t}+\beta_{3} G i n i_{i, t} * R S_{i, t}+\Theta X_{i, t}+\epsilon_{i, t}
$$

where $R L_{i, t}$ is the rule of law of country $i$ in period $t$ with each period covering three-yearly intervals, Gini $i_{i, t}$ is the Gini index from SWIID based on net income, $R S_{i, t}$ refers to natural resources, $X_{i, t}$ denotes a vector of control variables. This model seeks to determine the relationship among the rule of law, income inequality and natural resource-abundance. I also compare three assumptions about $\alpha_{i}$, which account for individual effects. These assumptions correspond to three econometric strategies: pooled OLS, the fixed effects model and the random effects model. The

\footnotetext{
${ }^{16}$ The fuel subsoil resources include oil rent, gas rent and coal rent. The non-fuel subsoil resources include various metals, like lead, gold, etc.
} 
effect of resource-abundance on the rule of law is given by $\beta_{2}+\beta_{3}$ Gini, where $\beta_{2}$ measures the direct effect of natural resource abundance on the rule of law, an effect which has been called the "blessing effect." The interaction term $\beta_{3} G i n i_{i, t} * R S_{i, t}$ is included in the regression to capture the effect of resource abundance on the rule of law as intermediated by the distribution of income. I cannot expect the sign of $\beta_{3}$ before the regressions, as I hypothesize that higher income inequality to lead to both predatory contests for abundant resources and an incentive and the means to institutionalize the rule of law.

\section{The Discussion About The Individual Effects}

My data set features two important characteristics that affect the decisions concerning the choice of econometric strategies in the static model. First, it is a short panel data set, including 193 countries and very limited number of periods. There are five periods in the WGI data set from 1996-2010, and nine periods in the ICRG data set from 1984-2010. Second, all variables in the original and the averaged data set are persistent over these periods for each country. Large variations in institution quality, resource-abundance, or the Gini index are rare within a country.

To see what is involved here, I plot all the observations of the rule of law from WGI and ICRG with blue hollow circles in the figure 2.3 and 2.4, respectively. Each maroon diamond sign represents the mean of the rule of law over all years for a given country. The figures show considerable variation across countries, illustrated by the vertical gaps between diamond signs. On the other hand, the hollow circles that surround each diamond sign show persistence of the rule of law within each country over these periods. These two conclusions are also supported by the figure 2.5

and 2.6, in which the diamond signs depict the means of the rule of law for all the countries in each period. The variation among countries in each period is shown 
by the spectrum of the values of the rule of law, spanning the entire vertical axis with no clearly discernible distribution. The persistence within each country is the only reason that can explain the stability of the diamond signs across all periods. The other possible explanation, which is unlikely to be valid, is that countries with a better rule of law drop in rankings by the same amount as the countries with a worse rule of law rise in each period.

The observations above imply that individual effects exist. I also run the fixed effects regressions and corresponding $\mathrm{F}$ tests to check them. The results are presented in the table 2.2 and 2.3. All the F tests at the bottom line reject the null hypothesis that all $u_{i}=0$ regardless of the significance level of each coefficient, and thus confirm the existence of individual effects. ${ }^{17}$

The next question I need to tackle is that of the choice between the fixed effects model and the random effects model. It is known that the the properties of the estimators in the random effects model are not affected by the two characteristics of my data set mentioned above. However, the estimators of the fixed effects model would be negatively affected as shown below.

- The estimation procedure of the fixed effects model absorbs the individual effects into the error term, reducing the possible bias associated with the problem of omitted variables if those individual effects are correlated with other regressors. This reduction in bias comes, however, at the cost of efficiency as it removes all cross-sectional variation from the data.(Higgins \& Williamson (1999)) This cost might be very significant since the variation of the variables are mainly across countries as I showed in the discussion above. To see this

${ }^{17}$ These $\mathrm{F}$ tests suggest that the fixed effects model is better than the pooled OLS model. Below I will argue that for my purposes the random effects model is more suitable than the fixed effects model. 
in detail, note that the estimator for the fixed effects model in the form of the equation 2.3 is the same as the pooled OLS estimator of the following equation, (Greene (2011))

$$
\begin{aligned}
R L_{i, t}-\overline{R L_{i}} & =\beta_{1}\left(\operatorname{Gini}_{i, t}-\overline{\operatorname{Gini}}_{i}\right)+\beta_{2}\left(R S_{i, t}-\overline{R S}_{i}\right) \\
& +\beta_{3}\left(\operatorname{Gini}_{i, t} * R S_{i, t}-{\overline{\operatorname{Gini}} * R S_{i}}_{i}\right)+\Theta\left(X_{i, t}-\bar{X}_{i}\right)+\left(\epsilon_{i, t}-\bar{\epsilon}_{i}\right)
\end{aligned}
$$

where the bar above each variable denotes the average over all years of that variable for each country $i$. The fixed effects estimator is thus equal to

$$
\beta_{F E}=\left[\sum_{i=1}^{N} \tilde{\mathbf{x}}_{i}^{\prime} \tilde{\mathbf{x}}_{i}\right]^{-1} \sum_{i=1}^{N} \tilde{\mathbf{x}}_{i}^{\prime} \tilde{\mathbf{R L}}_{i}
$$

where $\tilde{\mathbf{x}}_{i}=\left(\begin{array}{cccc}x_{i, 1,1}-\bar{x}_{i, 1} & x_{i, 1,2}-\bar{x}_{i, 2} & \cdots & x_{i, 1, k}-\bar{x}_{i, k} \\ x_{i, 2,1}-\bar{x}_{i, 1} & x_{i, 2,2}-\bar{x}_{i, 2} & \cdots & x_{i, 2, k}-\bar{x}_{i, k} \\ \vdots & \vdots & \ddots & \vdots \\ x_{i, T, 1}-\bar{x}_{i, 1} & x_{i, T, 2}-\bar{x}_{i, 2} & \cdots & x_{i, T, k}-\bar{x}_{i, k}\end{array}\right)$

The small variation within each country in my data set would set the above matrix close to zero and make the estimator unreliable. In an extreme but possible case, when the time-invariant regressor, $x_{i, k, t}$, was included, $\beta_{F E}$ could not be estimated because the matrix above became 0 .

- The $\beta_{F E}$ in the equation 2.5 is essentially an "average" of the within-group effects across the countries in the sample. The relatively small number of years, $T$, for the observations may lead to within-group effects that are highly sensitive to the sample drawn and diverge considerably from the true situation. This divergence may be corrected by increasing the number of countries, $N$. But it constitutes a potential problem when the of countries is also small, as they might all diverge in the same direction.(Clark \& Linzer (2012)) 
- The correlation between the regressors and the unit fixed effects are high when it comes to the ICRG data set. Such high correlations can greatly destabilize the estimates of the effects of the regressors, leading to unreliable inference (Clark \& Linzer (2012)).

\section{The Results}

Given the problems associated with the fixed effects model, I use the random effects model to estimate equation 2.3 for the entire panel data set. Table 2.4 presents the results. The dependent variable is the rule of law from WGI and ICRG, respectively. In models 2, 3 and 4, I successively include the democracy indicator and the size of government, both of which are estimated to have positive impacts on the rule of law. The last two columns include the secondary schooling attainment rate as an additional explanatory variable. As mentioned before, the inclusion of the interaction term "Gini * Rule of Law" allows me to explore the potentially important mechanism via which natural resources affect rule of law. As mentioned above, I hypothesize that abundant natural resources support the rule of law only when income disparity is small enough to reduce the incentives for predatory contests that may take extra-legal forms.

- The results from WGI data set provide evidence in support of my hypothesis. The opposite signs of $\beta_{2}$ and $\beta_{3}$ imply that there is a threshold value of Gini, beyond which (less equal distribution of income) more abundant natural resources will be associated with a deterioration in the rule of law. In the same vein if the Gini coefficient falls below this critical value (indicating a more equal distribution of income) more abundant natural resources are associated with higher values for the rule of law. Although this "blessing" effect is insignificant in some model specifications, the coefficient of the interaction term 
$\beta_{3}$ is significant across all the specifications except for model 2 where gold is chosen as the resources indicator.

- The effect of resource-abundance on the rule of law (WGI) as, for example, implied by model 5 is summarized by

$$
\begin{aligned}
& \frac{\partial(\text { rule of law })}{\partial(\text { resource abundance })}=0.1118-0.0038(\text { Gini index }) \text { oil as resources indicator } \\
& \frac{\partial(\text { rule of law })}{\partial(\text { resource abundance })}=0.0835-0.0024(\text { Gini index }) \text { goldas resources indicator }
\end{aligned}
$$

The critical value of the Gini index is $29.42 \%(0.1118 / 0.0038)$ and $34.79 \%$ $(0.0835-0.0024)$ for oil and gold, respectively. In my data set, 170 out of 193 countries has a mean Gini index greater than $29.42 \%$ and while 138 countries have Gini indeces greater than 34.79\%. This implies that the "blessing effect" of resource abundance in most countries in my sample is neutralized by inequalities in their income distributions.

- I also observe that the blessing effects are stronger and diminish faster (as indicated by the higher intercept and the absolute value of the slope coefficient) when I use oil as the resources indicator. The difference between oil and gold appears to be due to the difference in their profitability: oil is ranked among the top five most profitable commodities while gold is not (Barunik et al. (2013), Narayan et al. (2013)). ${ }^{18}$. As higher profits from oil raise the returns to predatory contests for it, the incentives to use extra-legal means in such contest would be stronger. These results are also consistent with Mehlum et al. (2006), who also found that the effects of resource abundance are much

\footnotetext{
${ }^{18} \mathrm{http}: / /$ cmegroup.com/education/featured-reports/cme-group-leading-products.html. Also note that both gold and oil have the greatest average trading volume among metals and energy commodities, respectively.
} 
stronger but diminish quicker when the resource indicator is changed to the share of mineral production in GNP from the share of primary exports in GNP. ${ }^{19}$

- When I investigate the models using the rule of law data from ICRG, the coefficients of the interaction terms are not significant for most specifications. However, the signs of the coefficients remain unchanged from the WGI data set. Unlike those for the WGI data set though, the constant terms in all ten regressions for ICRG are relatively high and significant, suggesting that there remains still some unobservable and significant individual effects. These effects are even more persistent than that in the rule of law data set from WGI. Those individual effects may be highly correlated with the explanatory variables, and thus yield biased estimators due to severe violations of the assumptions of random effects model. Consequently, I proceed to dynamic-panel estimation with system GMM estimator to explore the ICRG data set.

\subsubsection{The Dynamic Panel Results}

The regression equation I use for the dynamic panel estimations utilizes the oneperiod (taken to be three years here) lagged value of the rule of law as an explanatory variable. The specific equation I estimate is

$$
R L_{i, t}=\beta_{0} R L_{i, t-1}+\beta_{1} G i n i_{i, t}+\beta_{2} R S_{i, t}+\beta_{3} G i n i_{i, t} * R S_{i, t}+\Theta X_{i, t}+\alpha_{i}+\epsilon_{i, t}
$$

There are a number of reasons for adding the lagged value of the rule of law variable on the right hand side. First, the inclusion of lags is used to account for the partial adjustment of rule of law over time. Second, the impact of the changes in the

\footnotetext{
${ }^{19}$ Minerals have historically been more constestable compared to primary exports.
} 
explanatory variables, such as resource-abundance, may not be instantaneous and their effects may be persistent. Third, "including lags of the dependent variable as regressors...can also help eliminate serial correlation in the disturbance term "(Wawro (2002), Beck \& Katz (1996)). I also adopt the dynamic panel data (DPD) strategy to obtain the system GMM estimator (Holtz-Eakin et al. (1988); Arellano \& Bond (1991); Arellano \& Bover (1995) and Blundell \& Bond (2002)). This specific regression method helps address issues raised by my "small T, large N" panels (Roodman (2006)). As the WGI data set has only 5 periods and the instruments would quickly outnumber the groups in the system GMM estimator procedure, I only apply this methodology to the ICRG data set. For the same reason, I present the results for the ICRG data set using gold as my resource indicator in table 2.6 for comparison purposes only as in this case the instruments outnumber the groups even in the benchmark model. ${ }^{20}$ The introduction of the dynamic process should not change the underlying mechanism and here serves solely for the purpose of teasing out the econometric problems in the static model. Thus, a priori I would expect to obtain results for the ICRG data set with oil similar to those found before, including the signs of the coefficients and the critical value of the Gini index.

The results are presented in the table 2.5. Each model used consists of two regressions: the left column treats all the regressors as endogenous variables and instruments them with their own 4-period and 5-period lags. The only strictly exogenous variable is the time variable. The right column is the same as the left one except for the fact that it includes the Gini index of education as an additional instrumental variable. Model (4) and model (5) also have slightly more instruments than those for groups.

\footnotetext{
${ }^{20}$ Generally speaking, the number of instruments would increase with the number of explanatory variables being added, while the number of groups would not vary.
} 
- Table 2.5 shows that the coefficient of persistence for the rule of law is between 0.56 and 0.72 , depending on the model specifications, implying that $56 \%$ of a one-unit improvement in the rule of law today will be carried over to 3 years later. This indicates that previous values of the rule of law variable yield information about future values, suggesting that my dynamic setup is valid. I also note that this value is relatively stable across different model specifications and is robust to the inclusion of other variables. The estimated range is also consistent with the results in Chong \& Gradstein (2007), whose regressions present a range of $0.47-0.73$ for the coefficients of persistence of various institutional indicators after controlling for education and financial conditions.

- The effects of resource abundance are still positive and robust. The conclusions drawn from the random effects model using the WGI data set also receive additional support. Although absolute values of the coefficients are not comparable across different data sets, the greater magnitudes obtained (e.g. 0.2954 in ICRG v.s. 0.11 in WGI) using the ICRG data set (after teasing out the persistence factor) also support my initial hypothesis of diminishing "blessing" effects.

- Diminishing "blessing" effects are also robust across all the model specifications except for regression 9. One point of interest here is whether the implied critical value of the Gini index I estimate with the dynamic model is consistent with the results obtained from the static model. To see whether this is the case, note for example that in regression 10, the critical value is $37.66 \%$ $(0.2658 / 0.007057=37.66)$ and that the Gini indeces of 117 countries (out of 193 in the sample) exceed this number in my ICRG data set. Further, note also that this number is lower than what I found in the random effects model 
using the WGI data set with oil resources (170). Yet, it is close to what I

obtained (138) using the WGI data set with gold resources. Thus, the results from two different data sets using different econometric strategies provide evidence supporting my hypothesis and suggesting that my results are robust across data sets and estimation strategies.

\subsection{Conclusion}

The contribution of this paper is the comprehensive analysis of the effects of two indicators of the level of resource-abundance on the rule of law and its interaction with income inequality. The methodologies adopted are suitable for the inclusion of other resource indicators and institution variables.

My main findings are as follows. First, I indeed find that more resources correspond to better rule of law in a more equitable country. When social polarization becomes severe, the positive effects of resource-abundance level on the rule of law turn negative. Although the magnitudes may vary depending upon the choice of indicators, observed diminishing "blessing effects" of resources are robust across data sets and econometric methodologies.

Possible extensions of the current analysis include consideration of other dimensions of the rule of law such as political stability and crime rates. Another possible extension would be the compilation of a more comprehensive data set for resources, so that I can observe whether or not that diminishing bless effects persist across additional types of resources. 
Table 2.1: Correlation Between Rule of Law from WGI and ICRG

\begin{tabular}{cc}
\hline Correlation & Year \\
\hline 0.7779 & Whole Data set \\
0.8246 & 1996 \\
0.8031 & 1998 \\
0.7627 & 2000 \\
0.7503 & 2002 \\
0.7532 & 2003 \\
0.7724 & 2004 \\
0.7880 & 2005 \\
0.7849 & 2006 \\
0.7957 & 2007 \\
0.8113 & 2008 \\
0.8061 & 2009 \\
0.8003 & 2010 \\
\hline
\end{tabular}


Table 2.2: Existing Individual Effects in WGI Data Set

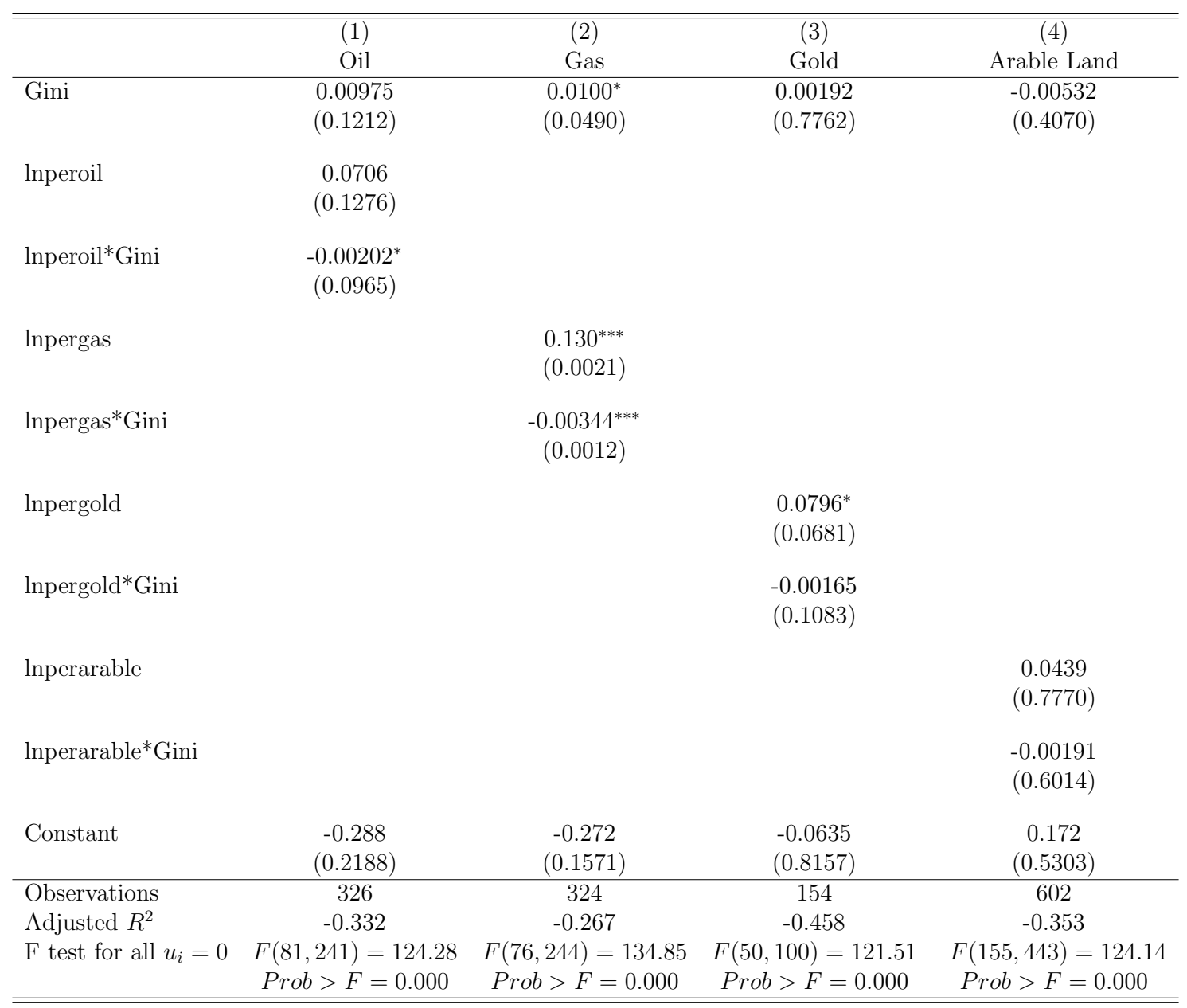

$p$-values in parentheses

${ }^{*} p<0.10,{ }^{* *} p<0.05,{ }^{* * *} p<0.01$ 
Table 2.3: Existing Individual Effects in ICRG Data Set

\begin{tabular}{|c|c|c|c|c|}
\hline & $\begin{array}{l}(1) \\
\text { Oil }\end{array}$ & $\begin{array}{l}\text { (2) } \\
\text { Gas }\end{array}$ & $\begin{array}{c}(3) \\
\text { Gold }\end{array}$ & $\begin{array}{c}(4) \\
\text { Arable Land }\end{array}$ \\
\hline Gini & $\begin{array}{c}0.0497^{* * *} \\
(0.0052)\end{array}$ & $\begin{array}{l}0.0280^{*} \\
(0.0630)\end{array}$ & $\begin{array}{c}0.0209 \\
(0.2626)\end{array}$ & $\begin{array}{l}-0.00619 \\
(0.7084)\end{array}$ \\
\hline lnperoil & $\begin{array}{l}-0.264^{*} \\
(0.0725)\end{array}$ & & & \\
\hline lnperoil*Gini & $\begin{array}{c}-0.000268 \\
(0.9414)\end{array}$ & & & \\
\hline lnpergas & & $\begin{array}{c}-0.201 \\
(0.1412)\end{array}$ & & \\
\hline lnpergas*Gini & & $\begin{array}{l}0.00511 \\
(0.1432)\end{array}$ & & \\
\hline lnpergold & & & $\begin{array}{c}0.0342 \\
(0.8159)\end{array}$ & \\
\hline lnpergold*Gini & & & $\begin{array}{r}-0.00151 \\
(0.6539)\end{array}$ & \\
\hline lnperarable & & & & $\begin{array}{l}-0.0776 \\
(0.8464)\end{array}$ \\
\hline lnperarable*Gini & & & & $\begin{array}{l}-0.00863 \\
(0.3382)\end{array}$ \\
\hline Constant & $\begin{array}{l}2.928^{* * *} \\
(0.0000)\end{array}$ & $\begin{array}{l}3.080^{* * *} \\
(0.0000)\end{array}$ & $\begin{array}{l}2.874^{* * *} \\
(0.0002)\end{array}$ & $\begin{array}{l}3.351^{* * *} \\
(0.0000)\end{array}$ \\
\hline $\begin{array}{l}\text { Observations } \\
\text { Adjusted } R^{2}\end{array}$ & $\begin{array}{c}507 \\
-0.082\end{array}$ & $\begin{array}{c}498 \\
-0.151\end{array}$ & $\begin{array}{c}296 \\
-0.209\end{array}$ & $\begin{array}{c}840 \\
-0.161\end{array}$ \\
\hline F test for all $u_{i}=0$ & $\begin{array}{l}F(76,427)=12.22 \\
\text { Prob }>F=0.000\end{array}$ & $\begin{array}{l}F(70,424)=11.70 \\
\text { Prob }>F=0.000\end{array}$ & $\begin{array}{l}F(51,241)=9.67 \\
\text { Prob }>F=0.000\end{array}$ & $\begin{array}{l}F(124,712)=13.56 \\
\text { Prob }>F=0.000\end{array}$ \\
\hline
\end{tabular}


Table 2.4: Random Effects Model Results

\begin{tabular}{|c|c|c|c|c|c|c|c|c|c|c|}
\hline & \multicolumn{2}{|c|}{$\begin{array}{c}(1) \\
\text { (Benchmark) }\end{array}$} & \multicolumn{2}{|c|}{$\begin{array}{c}(2) \\
\text { (Gov Size) }\end{array}$} & \multicolumn{2}{|c|}{$\begin{array}{c}(3) \\
\text { (Democracy) }\end{array}$} & \multicolumn{2}{|c|}{$\begin{array}{c}(4) \\
\text { (Both) }\end{array}$} & \multicolumn{2}{|c|}{$\begin{array}{l}\text { (5) } \\
\text { (All) }\end{array}$} \\
\hline & RL(WGI) & RL(ICRG) & RL(WGI) & RL(ICRG) & RL(WGI) & RL(ICRG) & RL(WGI) & RL(ICRG) & RL(WGI) & RL(ICRG) \\
\hline \multicolumn{11}{|l|}{ I. Oil as RS } \\
\hline Gini & $\begin{array}{l}0.0037 \\
(0.006)\end{array}$ & $\begin{array}{c}-0.0156 \\
(0.013)\end{array}$ & $\begin{array}{l}0.0047 \\
(0.006)\end{array}$ & $\begin{array}{c}-0.0238^{*} \\
(0.013)\end{array}$ & $\begin{array}{l}0.0010 \\
(0.006)\end{array}$ & $\begin{array}{c}-0.0238^{*} \\
(0.012)\end{array}$ & $\begin{array}{l}0.0029 \\
(0.006)\end{array}$ & $\begin{array}{c}-0.0271^{* *} \\
(0.012)\end{array}$ & $\begin{array}{l}0.0026 \\
(0.006)\end{array}$ & $\begin{array}{r}-0.0172 \\
(0.013)\end{array}$ \\
\hline Resources & $\begin{array}{l}0.0687 \\
(0.046)\end{array}$ & $\begin{array}{l}0.0150 \\
(0.116)\end{array}$ & $\begin{array}{c}0.1106^{* *} \\
(0.048)\end{array}$ & $\begin{array}{l}0.0853 \\
(0.113)\end{array}$ & $\begin{array}{l}0.0768 \\
(0.047)\end{array}$ & $\begin{array}{l}0.0419 \\
(0.109)\end{array}$ & $\begin{array}{l}0.1180 \\
(0.047)\end{array}$ & $\begin{array}{l}0.1114 \\
(0.108)\end{array}$ & $\begin{array}{c}0.1118^{* *} \\
(0.056)\end{array}$ & $\begin{array}{l}0.1673 \\
(0.116)\end{array}$ \\
\hline Gini*Resources & $\begin{array}{c}-0.0022^{*} \\
(0.001)\end{array}$ & $\begin{array}{l}-0.0033 \\
(0.003)\end{array}$ & $\begin{array}{c}-0.0035^{* * *} \\
(0.001)\end{array}$ & $\begin{array}{l}-0.0045 \\
(0.003)\end{array}$ & $\begin{array}{c}-0.0027^{* *} \\
(0.001)\end{array}$ & $\begin{array}{l}-0.0032 \\
(0.003)\end{array}$ & $\begin{array}{c}-0.0039^{* * * *} \\
(0.001)\end{array}$ & $\begin{array}{l}-0.0046 \\
(0.003)\end{array}$ & $\begin{array}{c}-0.0038^{* * *} \\
(0.001)\end{array}$ & $\begin{array}{c}-0.0066^{* *} \\
(0.003)\end{array}$ \\
\hline Gov Size & & & $\begin{array}{c}0.0226^{* * *} \\
(0.007)\end{array}$ & $\begin{array}{l}0.0314 \\
(0.013)\end{array}$ & & & $\begin{array}{c}0.0251^{* * * *} \\
(0.007)\end{array}$ & $\begin{array}{l}0.0228^{*} \\
(0.013)\end{array}$ & $\begin{array}{c}0.0174^{* * * *} \\
(0.007)\end{array}$ & $\begin{array}{c}0.0324^{* *} \\
(0.015)\end{array}$ \\
\hline Democracy & & & & & $\begin{array}{c}0.0669^{* * *} \\
(0.009)\end{array}$ & $\begin{array}{c}0.0979^{* * *} \\
(0.017)\end{array}$ & $\begin{array}{c}0.0655^{* * * *} \\
(0.009)\end{array}$ & $\begin{array}{c}0.0860^{* * *} \\
(0.018)\end{array}$ & $\begin{array}{c}0.0562^{* * * *} \\
(0.009)\end{array}$ & $\begin{array}{c}0.0591^{* * *} \\
(0.021)\end{array}$ \\
\hline Education & & & & & & & & & $\begin{array}{l}0.2862 \\
(0.278)\end{array}$ & $\begin{array}{c}1.0691^{* *} \\
(0.479)\end{array}$ \\
\hline Constant & $\begin{array}{c}-0.1409 \\
(0.251)\end{array}$ & $\begin{array}{c}4.7452^{* * *} \\
(0.500)\end{array}$ & $\begin{array}{c}-0.4732^{*} \\
(0.086)\end{array}$ & $\begin{array}{c}4.5189 \\
0.559\end{array}$ & $\begin{array}{c}-0.4129^{*} \\
(0.249)\end{array}$ & $\begin{array}{l}4.3765 \\
(0.476)\end{array}$ & $\begin{array}{c}-0.8294^{* * *} \\
(0.270)\end{array}$ & $\begin{array}{c}4.1867^{* * *} \\
0.539\end{array}$ & $\begin{array}{c}-0.06858^{* * *} \\
(0.310)\end{array}$ & $\begin{array}{c}3.4558^{* * *} \\
(0.582)\end{array}$ \\
\hline $\mathrm{N}$ & 326 & 507 & 319 & 492 & 325 & 507 & 318 & 492 & 293 & 481 \\
\hline$R^{2}$ & 0.1781 & 0.1334 & 0.3706 & 0.2969 & 0.5889 & 0.3571 & 0.6368 & 0.4170 & 0.5914 & 0.4267 \\
\hline II. Gold as RS & & & & & & & & & & \\
\hline Gini & $\begin{array}{c}0.0109^{*} \\
(0.006)\end{array}$ & $\begin{array}{c}-0.0499^{* * *} \\
(0.012)\end{array}$ & $\begin{array}{l}-0.0081 \\
(0.006)\end{array}$ & $\begin{array}{c}-0.0598^{* * *} \\
(0.012)\end{array}$ & $\begin{array}{c}-0.0188^{* * *} \\
(0.006)\end{array}$ & $\begin{array}{c}-0.0453^{* * *} \\
(0.012)\end{array}$ & $\begin{array}{c}-0.0159^{* * *} \\
(0.006)\end{array}$ & $\begin{array}{c}-0.0527^{* * *} \\
(0.011)\end{array}$ & $\begin{array}{c}-0.0177^{* * *} \\
(0.007)\end{array}$ & $\begin{array}{c}-0.0439^{* * *} \\
(0.012)\end{array}$ \\
\hline Resources & $\begin{array}{c}0.1122^{* *} \\
(0.045)\end{array}$ & $\begin{array}{l}0.1687 \\
(0.130)\end{array}$ & $\begin{array}{l}0.0576 \\
(0.044)\end{array}$ & $\begin{array}{r}0.1401 \\
(1.08)\end{array}$ & $\begin{array}{c}0.1421^{* * *} \\
(0.048)\end{array}$ & $\begin{array}{l}0.2022 \\
(0.125)\end{array}$ & $\begin{array}{c}0.0786^{*} \\
(0.047)\end{array}$ & $\begin{array}{l}0.1592 \\
(0.126)\end{array}$ & $\begin{array}{l}0.0835^{*} \\
(0.048)\end{array}$ & $\begin{array}{c}0.1302 \\
(0.1249)\end{array}$ \\
\hline Gini*Resources & $\begin{array}{c}-0.0023^{* *} \\
(0.001)\end{array}$ & $\begin{array}{l}-0.0042 \\
(0.003)\end{array}$ & $\begin{array}{l}-0.0015 \\
(0.001)\end{array}$ & $\begin{array}{l}-0.0038 \\
(0.199)\end{array}$ & $\begin{array}{c}-0.0032^{* * *} \\
(0.001)\end{array}$ & $\begin{array}{c}-0.0056^{*} \\
(0.003)\end{array}$ & $\begin{array}{c}-0.0020^{*} \\
(0.001)\end{array}$ & $\begin{array}{r}-0.0047 \\
(0.003)\end{array}$ & $\begin{array}{c}-0.0024^{* *} \\
(0.001)\end{array}$ & $\begin{array}{l}0.0044 \\
(0.003)\end{array}$ \\
\hline Gov Size & & & $\begin{array}{c}0.0437^{* * * *} \\
(0.008)\end{array}$ & $\begin{array}{c}0.0332^{*} \\
(0.018)\end{array}$ & & & $\begin{array}{c}0.0396^{* * *} \\
(0.009)\end{array}$ & $\begin{array}{c}0.0295^{*} \\
(0.018)\end{array}$ & $\begin{array}{c}0.0434^{* * *} \\
(0.009)\end{array}$ & $\begin{array}{l}0.0244 \\
(0.018)\end{array}$ \\
\hline Democracy & & & & & $\begin{array}{c}0.0535^{\text {*** }} \\
(0.012)\end{array}$ & $\begin{array}{c}0.1035^{\text {**** }} \\
(0.023)\end{array}$ & $\begin{array}{c}0.0441^{* * * *} \\
(0.012)\end{array}$ & $\begin{array}{c}0.0895^{* * *} \\
(0.023)\end{array}$ & $\begin{array}{c}0.0389^{* * *} \\
(0.012)\end{array}$ & $\begin{array}{c}0.0931^{* * * *} \\
(0.024)\end{array}$ \\
\hline Education & & & & & & & & & $\begin{array}{c}0.785^{*} \\
(0.402)\end{array}$ & $\begin{array}{l}0.8364 \\
(0.613)\end{array}$ \\
\hline Constant & $\begin{array}{l}0.2963 \\
(0.296) \\
\end{array}$ & $\begin{array}{c}5.5842^{\text {**** }} \\
(0.533)\end{array}$ & $\begin{array}{r}-0.4457 \\
(0.309)\end{array}$ & $\begin{array}{c}5.5372^{* * *} \\
(0.589)\end{array}$ & $\begin{array}{c}0.293 \\
(0.295)\end{array}$ & $\begin{array}{c}4.7573^{* * *} \\
(0.546)\end{array}$ & $\begin{array}{c}-0.3385 \\
(0.311)\end{array}$ & $\begin{array}{c}4.7405^{* * *} \\
(0.609)\end{array}$ & $\begin{array}{c}-0.5806 \\
(0.02)\end{array}$ & $\begin{array}{c}4.0973^{* * *} \\
(0.671)\end{array}$ \\
\hline $\mathrm{N}$ & 154 & 296 & 152 & 289 & 154 & 296 & 152 & 289 & 146 & 275 \\
\hline$R^{2}$ & 0.3461 & 0.3924 & 0.4100 & 0.4906 & 0.6585 & 0.4672 & 0.6684 & 0.5300 & 0.6727 & 0.5467 \\
\hline
\end{tabular}

Table 2.5: DPD estimator for ICRG data set (Oil)

\begin{tabular}{|c|c|c|c|c|c|c|c|c|c|c|}
\hline & \multicolumn{2}{|c|}{ Benchmark } & \multicolumn{2}{|c|}{ Gov Size } & \multicolumn{2}{|c|}{$\begin{array}{l}\text { Democracy } \\
\end{array}$} & \multicolumn{2}{|c|}{ Both } & \multicolumn{2}{|c|}{ Hybrid } \\
\hline & (1) & (2) & (3) & (4) & (5) & (6) & (7) & (8) & (9) & (10) \\
\hline L.rl & $\begin{array}{c}0.5988^{* * *} \\
(0.065)\end{array}$ & $\begin{array}{c}0.7236^{* * *} \\
(0.062)\end{array}$ & $\begin{array}{c}0.5574^{* * *} \\
(0.062)\end{array}$ & $\begin{array}{c}0.6752^{* * *} \\
(0.061)\end{array}$ & $\begin{array}{c}0.5738^{* * *} \\
(0.061)\end{array}$ & $\begin{array}{c}0.6054^{* * *} \\
(0.053)\end{array}$ & $\begin{array}{c}0.5570^{* * *} \\
(0.058)\end{array}$ & $\begin{array}{c}0.6094^{* * *} \\
(0.062)\end{array}$ & $\begin{array}{c}0.6272^{* * *} \\
(0.051)\end{array}$ & $\begin{array}{c}0.6748^{* * *} \\
(0.061)\end{array}$ \\
\hline Gini & $\begin{array}{c}0.001528 \\
(0.017)\end{array}$ & $\begin{array}{c}0.004213 \\
(0.016)\end{array}$ & $\begin{array}{c}0.009433 \\
(0.017)\end{array}$ & $\begin{array}{c}0.01465 \\
(0.019)\end{array}$ & $\begin{array}{c}0.003707 \\
(0.014)\end{array}$ & $\begin{array}{c}0.005124 \\
(0.017)\end{array}$ & $\begin{array}{c}0.01094 \\
(0.019)\end{array}$ & $\begin{array}{c}0.01476 \\
(0.018)\end{array}$ & $\begin{array}{c}-0.004167 \\
(0.017)\end{array}$ & $\begin{array}{c}0.003095 \\
(0.017)\end{array}$ \\
\hline oil & $\begin{array}{c}0.3097^{*} \\
(0.172)\end{array}$ & $\begin{array}{c}0.3941^{* *} \\
(0.172)\end{array}$ & $\begin{array}{c}0.2668^{* *} \\
(0.115)\end{array}$ & $\begin{array}{c}0.3835^{* *} \\
(0.189)\end{array}$ & $\begin{array}{c}0.3224^{* *} \\
(0.128)\end{array}$ & $\begin{array}{c}0.3947^{* * *} \\
(0.145)\end{array}$ & $\begin{array}{c}0.2954^{* *} \\
(0.143)\end{array}$ & $\begin{array}{c}0.3931^{* * *} \\
(0.147)\end{array}$ & $\begin{array}{l}0.1962 \\
(0.135)\end{array}$ & $\begin{array}{c}0.2658^{* *} \\
(0.130)\end{array}$ \\
\hline Gini*oil & $\begin{array}{c}-0.009530^{* *} \\
(0.005)\end{array}$ & $\begin{array}{c}-0.01094^{* *} \\
(0.004)\end{array}$ & $\begin{array}{c}-0.008102^{* * *} \\
\quad(0.003)\end{array}$ & $\begin{array}{c}-0.01019^{* *} \\
(0.005)\end{array}$ & $\begin{array}{c}-0.009190^{* *} \\
(0.004)\end{array}$ & $\begin{array}{c}-0.01073^{* * *} \\
\quad(0.004)\end{array}$ & $\begin{array}{c}-0.008294^{* *} \\
(0.004)\end{array}$ & $\begin{array}{c}-0.01039^{* * *} \\
\quad(0.004)\end{array}$ & $\begin{array}{c}-0.005361 \\
(0.004)\end{array}$ & $\begin{array}{c}-0.007057^{* *} \\
(0.004)\end{array}$ \\
\hline government size & & & $\begin{array}{c}0.03616^{*} \\
(0.021)\end{array}$ & $\begin{array}{c}0.04145^{* *} \\
(0.018)\end{array}$ & & & $\begin{array}{c}0.03395^{*} \\
(0.019)\end{array}$ & $\begin{array}{c}0.03035 \\
(0.023)\end{array}$ & $\begin{array}{c}0.02842 \\
(0.023)\end{array}$ & $\begin{array}{c}0.02325 \\
(0.020)\end{array}$ \\
\hline democracy & & & & & $\begin{array}{c}0.03645^{*} \\
(0.019)\end{array}$ & $\begin{array}{c}0.06322^{* * *} \\
(0.023)\end{array}$ & $\begin{array}{c}0.02314 \\
(0.020)\end{array}$ & $\begin{array}{c}0.04135^{*} \\
(0.022)\end{array}$ & $\begin{array}{c}0.02995 \\
(0.021)\end{array}$ & $\begin{array}{c}0.05229^{* *} \\
(0.023)\end{array}$ \\
\hline education & & & & & & & & & $\begin{array}{c}-0.7482 \\
(0.459)\end{array}$ & $\begin{array}{c}-0.6156 \\
(0.498)\end{array}$ \\
\hline Constant & $\begin{array}{c}1.7341^{* *} \\
(0.691)\end{array}$ & $\begin{array}{l}1.0220 \\
(0.653)\end{array}$ & $\begin{array}{l}0.9887 \\
(0.957)\end{array}$ & $\begin{array}{l}0.1426 \\
(0.941)\end{array}$ & $\begin{array}{c}1.4154^{* *} \\
(0.593)\end{array}$ & $\begin{array}{l}1.0079 \\
(0.723)\end{array}$ & $\begin{array}{l}0.7542 \\
(0.942) \\
\end{array}$ & $\begin{array}{l}0.2929 \\
(0.898)\end{array}$ & $\begin{array}{l}1.3641 \\
(0.867)\end{array}$ & $\begin{array}{l}0.7684 \\
(0.777)\end{array}$ \\
\hline p-value of Hansen Test & 0.219 & 0.214 & 0.492 & 0.534 & 0.504 & 0.437 & 0.795 & 0.886 & 0.986 & 0.994 \\
\hline p-value of 3rd-order Correlation & 0.329 & 0.477 & 0.508 & 0.672 & 0.350 & 0.471 & 0.551 & 0.645 & 0.639 & 0.707 \\
\hline Observations & 447 & 429 & 435 & 426 & 447 & 429 & 435 & 426 & 426 & 426 \\
\hline
\end{tabular}


Table 2.6: DPD estimator for ICRG data set (Gold)

\begin{tabular}{|c|c|c|c|c|c|c|c|c|c|c|}
\hline & \multicolumn{2}{|c|}{ Benchmark } & \multicolumn{2}{|c|}{ "Gov Size } & \multicolumn{2}{|c|}{ Democracy } & \multicolumn{2}{|c|}{ Both } & \multicolumn{2}{|c|}{ "Hybrid } \\
\hline & (1) & $(2)$ & $(3)$ & (4) & $(5)$ & $(6)$ & $(7)$ & $(8)$ & (9) & $(10)$ \\
\hline L.rl_icrg & $\begin{array}{c}0.6984^{* * *} \\
(0.091)\end{array}$ & $\begin{array}{c}0.7280^{* * *} \\
(0.077)\end{array}$ & $\begin{array}{c}0.6016^{* * *} \\
(0.076)\end{array}$ & $\begin{array}{c}0.6442^{* * *} \\
(0.075)\end{array}$ & $\begin{array}{c}0.6946^{* * *} \\
(0.088)\end{array}$ & $\begin{array}{c}0.7666^{* * *} \\
(0.077)\end{array}$ & $\begin{array}{c}0.6623^{* * *} \\
(0.080)\end{array}$ & $\begin{array}{c}0.6728^{* * *} \\
(0.058)\end{array}$ & $\begin{array}{c}0.6854^{* * *} \\
(0.060)\end{array}$ & $\begin{array}{c}0.6822^{* * *} \\
(0.057)\end{array}$ \\
\hline Gini & $\begin{array}{c}-0.03626 \\
(0.022)\end{array}$ & $\begin{array}{c}-0.02734 \\
(0.016)\end{array}$ & $\begin{array}{c}-0.03831^{* *} \\
(0.017)\end{array}$ & $\begin{array}{c}-0.02946^{*} \\
(0.015)\end{array}$ & $\begin{array}{c}-0.03363^{*} \\
(0.017)\end{array}$ & $\begin{array}{c}-0.02692 \\
(0.018)\end{array}$ & $\begin{array}{c}-0.03546^{* *} \\
(0.015)\end{array}$ & $\begin{array}{c}-0.02737^{* *} \\
(0.012)\end{array}$ & $\begin{array}{c}-0.03012^{* *} \\
(0.012)\end{array}$ & $\begin{array}{c}-0.03029^{* *} \\
(0.013)\end{array}$ \\
\hline gold & $\begin{array}{c}0.4968^{* *} \\
(0.192)\end{array}$ & $\begin{array}{l}0.3592 \\
(0.226)\end{array}$ & $\begin{array}{l}0.1599 \\
(0.202)\end{array}$ & $\begin{array}{l}0.1458 \\
(0.150)\end{array}$ & $\begin{array}{c}0.4505^{* *} \\
(0.222)\end{array}$ & $\begin{array}{l}0.3133 \\
(0.192)\end{array}$ & $\begin{array}{l}0.2009 \\
(0.201)\end{array}$ & $\begin{array}{l}0.1627 \\
(0.148)\end{array}$ & $\begin{array}{l}0.1911 \\
(0.223)\end{array}$ & $\begin{array}{l}0.1785 \\
(0.128)\end{array}$ \\
\hline Gini*gold & $\begin{array}{c}-0.01116^{* *} \\
(0.004)\end{array}$ & $\begin{array}{c}-0.007763 \\
(0.005)\end{array}$ & $\begin{array}{c}-0.003922 \\
(0.005)\end{array}$ & $\begin{array}{c}-0.003769 \\
(0.003)\end{array}$ & $\begin{array}{c}-0.01025^{* *} \\
(0.005)\end{array}$ & $\begin{array}{c}-0.006762 \\
(0.004)\end{array}$ & $\begin{array}{c}-0.004646 \\
(0.005)\end{array}$ & $\begin{array}{c}-0.003609 \\
(0.004)\end{array}$ & $\begin{array}{c}-0.004038 \\
(0.005)\end{array}$ & $\begin{array}{c}-0.003827 \\
(0.003)\end{array}$ \\
\hline government size & & & $\begin{array}{c}0.05897^{* *} \\
(0.028)\end{array}$ & $\begin{array}{c}0.07673^{* * *} \\
(0.027)\end{array}$ & & & $\begin{array}{c}0.05215^{*} \\
(0.028)\end{array}$ & $\begin{array}{c}0.08123^{* * *} \\
(0.025)\end{array}$ & $\begin{array}{c}0.05452^{*} \\
(0.029)\end{array}$ & $\begin{array}{c}0.06147^{* *} \\
(0.026)\end{array}$ \\
\hline democracy & & & & & $\begin{array}{c}-0.008102 \\
(0.030)\end{array}$ & $\begin{array}{c}-0.02623 \\
(0.027)\end{array}$ & $\begin{array}{c}-0.02532 \\
(0.032)\end{array}$ & $\begin{array}{c}-0.02875 \\
(0.037)\end{array}$ & $\begin{array}{c}-0.01302 \\
(0.030)\end{array}$ & $\begin{array}{c}-0.02019 \\
(0.030)\end{array}$ \\
\hline Education & & & & & & & & & $\begin{array}{l}0.2727 \\
(0.469)\end{array}$ & $\begin{array}{l}0.1068 \\
(0.515)\end{array}$ \\
\hline Constant & $\begin{array}{c}2.6537^{* *} \\
(1.184) \\
\end{array}$ & $\begin{array}{c}2.1980^{* *} \\
(0.897)\end{array}$ & $\begin{array}{c}2.2064^{* *} \\
(0.991) \\
\end{array}$ & $\begin{array}{l}1.4436^{*} \\
(0.734) \\
\end{array}$ & $\begin{array}{c}2.6177^{* * *} \\
(0.901)\end{array}$ & $\begin{array}{c}2.2149^{* *} \\
(1.013) \\
\end{array}$ & $\begin{array}{c}2.1390^{* *} \\
(0.824) \\
\end{array}$ & $\begin{array}{c}1.3792^{* *} \\
(0.677)\end{array}$ & $\begin{array}{c}1.6305^{* *} \\
(0.630) \\
\end{array}$ & $\begin{array}{c}1.6654^{* *} \\
(0.726) \\
\end{array}$ \\
\hline p-value of Hansen Test & 0.874 & 0.927 & 0.988 & 0.993 & 0.962 & 0.990 & 0.998 & 1.000 & 0.916 & 1.000 \\
\hline p-value of 3rd-order Correlation & 0.752 & 0.736 & 0.819 & 0.855 & 0.720 & 0.727 & 0.885 & 0.929 & 1.000 & 0.918 \\
\hline Observations & 256 & 241 & 251 & 239 & 256 & 241 & 251 & 239 & 239 & 239 \\
\hline
\end{tabular}

Standard errors in parentheses

${ }^{+} p<0.10,{ }^{*} p<0.05,{ }^{* *} p<0.01,{ }^{* * *} p<0.001$ 
Figure 2.1: Gini(Disposable Income) Heterogeneity across Countries

The Heterogeneity of Gini across Countries

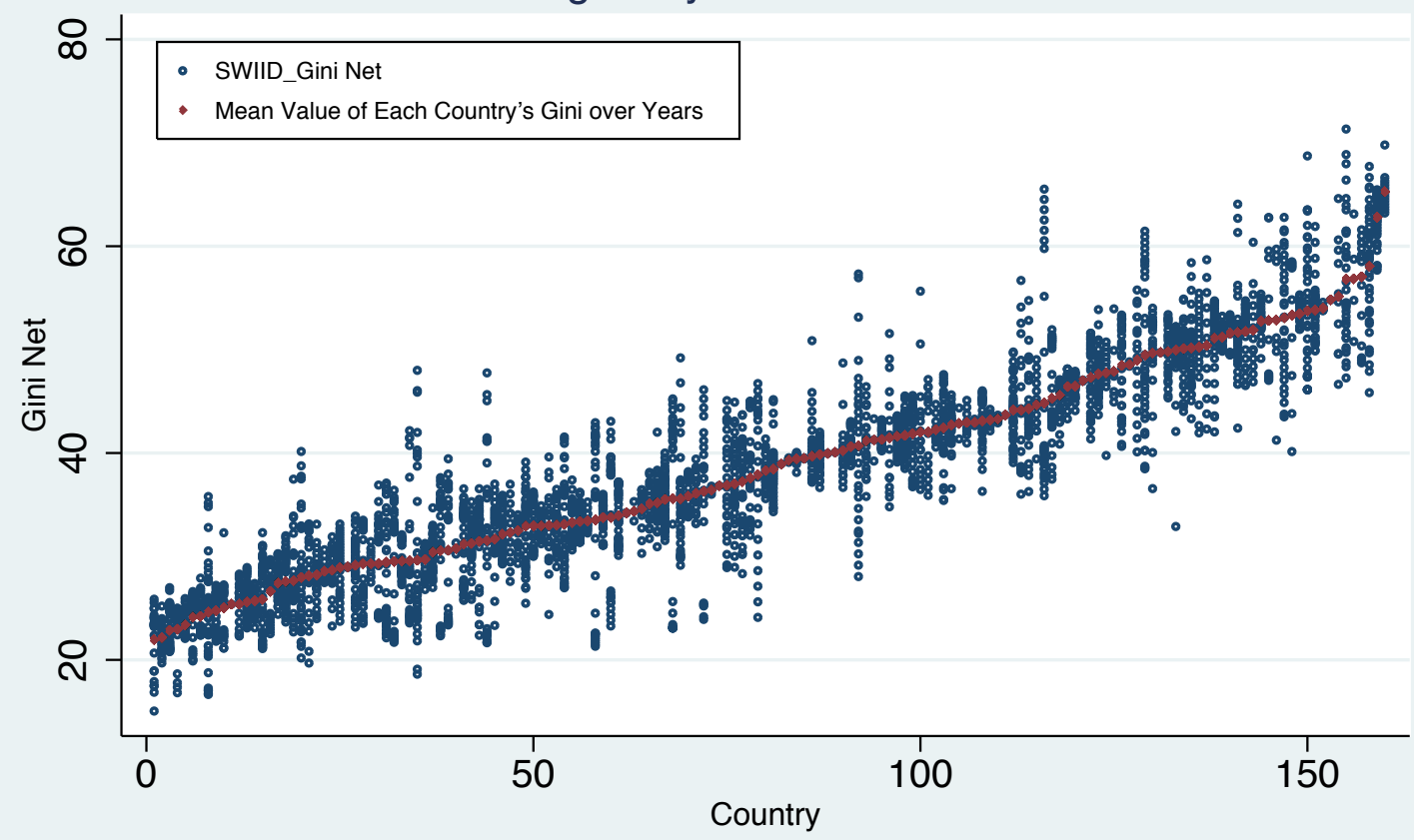

Data Source: SWIID Version 3.1, December 2011 
Figure 2.2: Similarity Between Rule of Law from WGI and ICRG

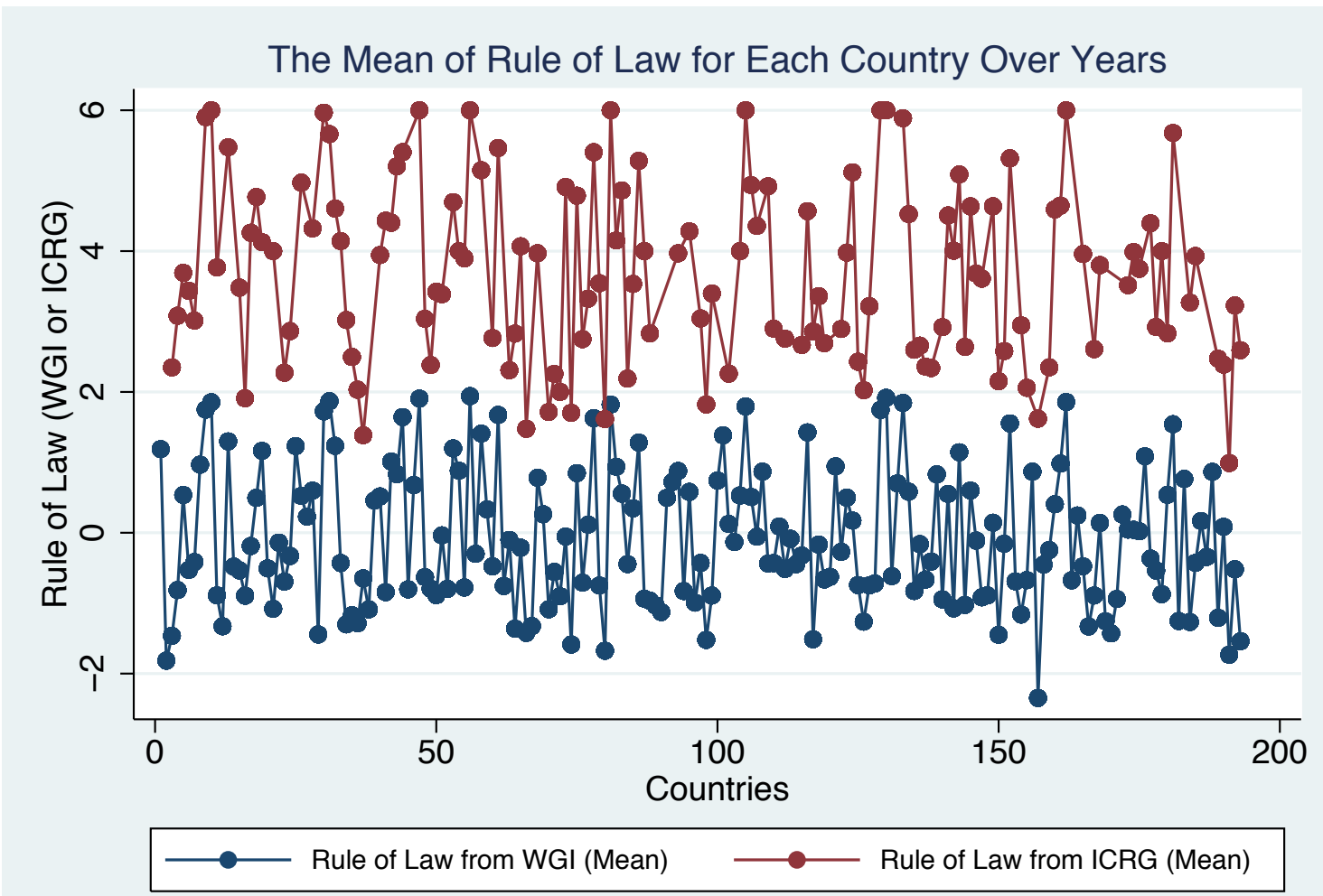

Data Source: World Governance Indicators (2012), International Country Risk Guide (2010) 
Figure 2.3: The Heterogeneity of Rule of Law Across All Countries (WGI)

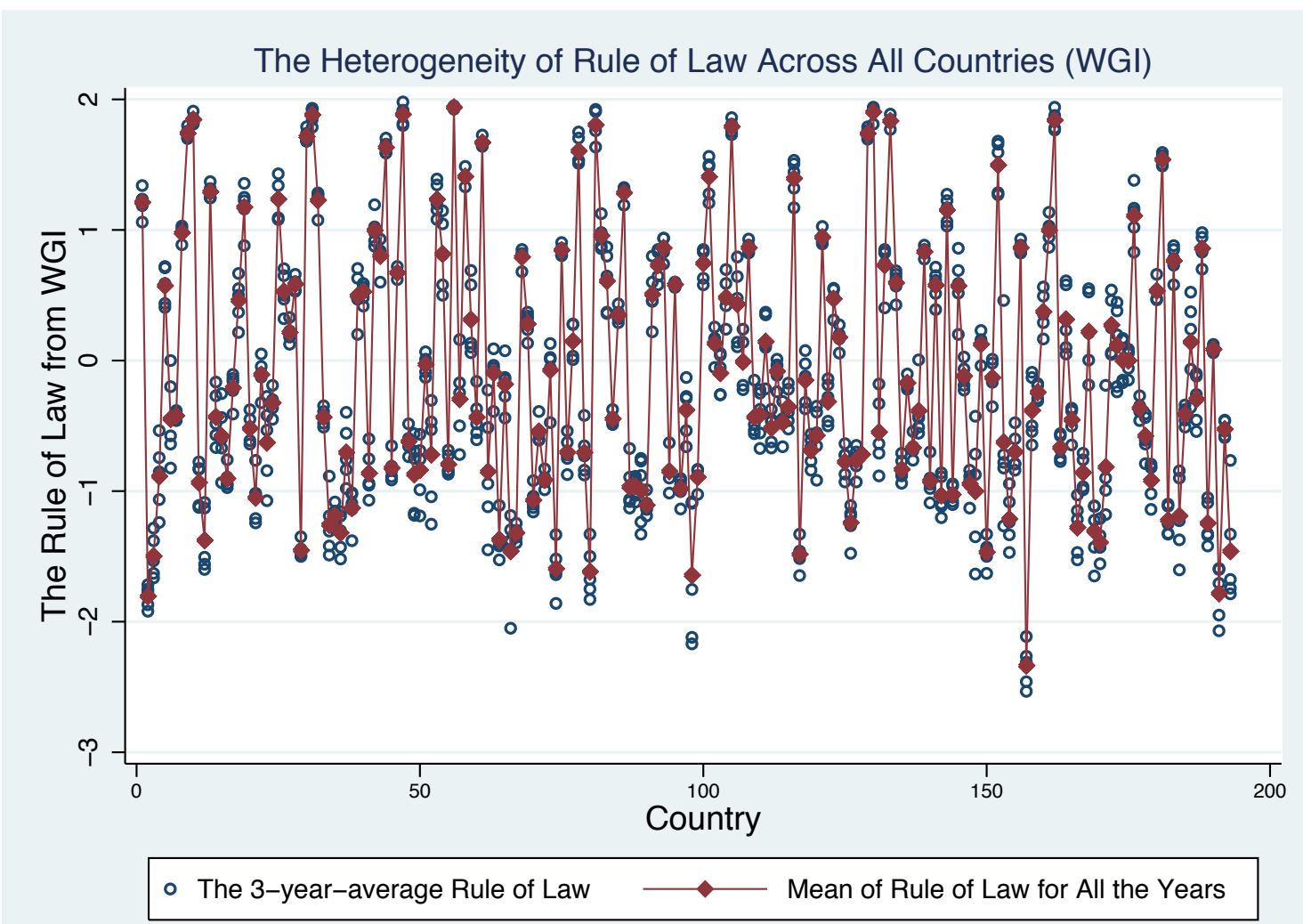


Figure 2.4: The Heterogeneity of Rule of Law Across All Countries (ICRG)

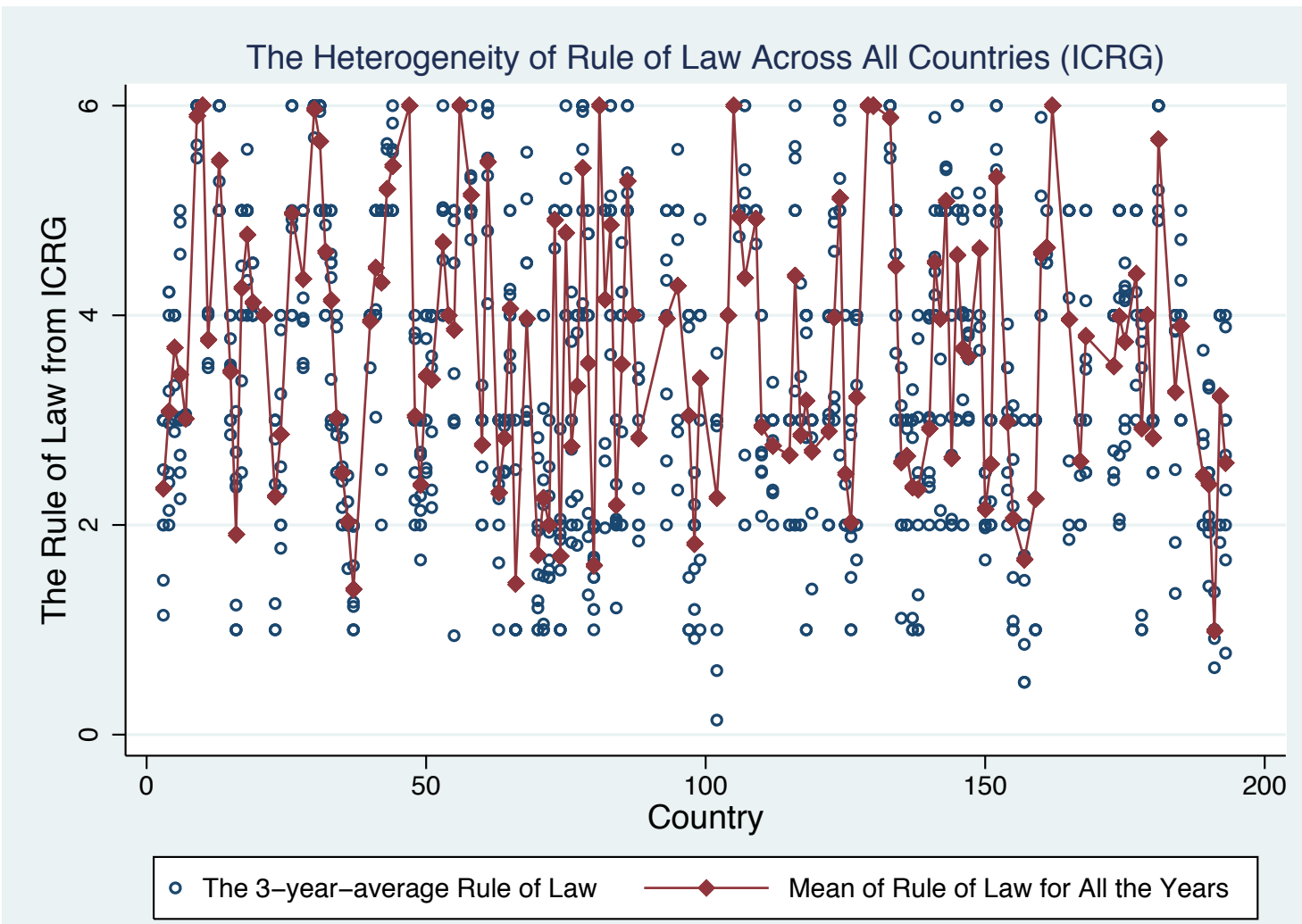


Figure 2.5: The Heterogeneity of the Rule of Law Across Periods (WGI)

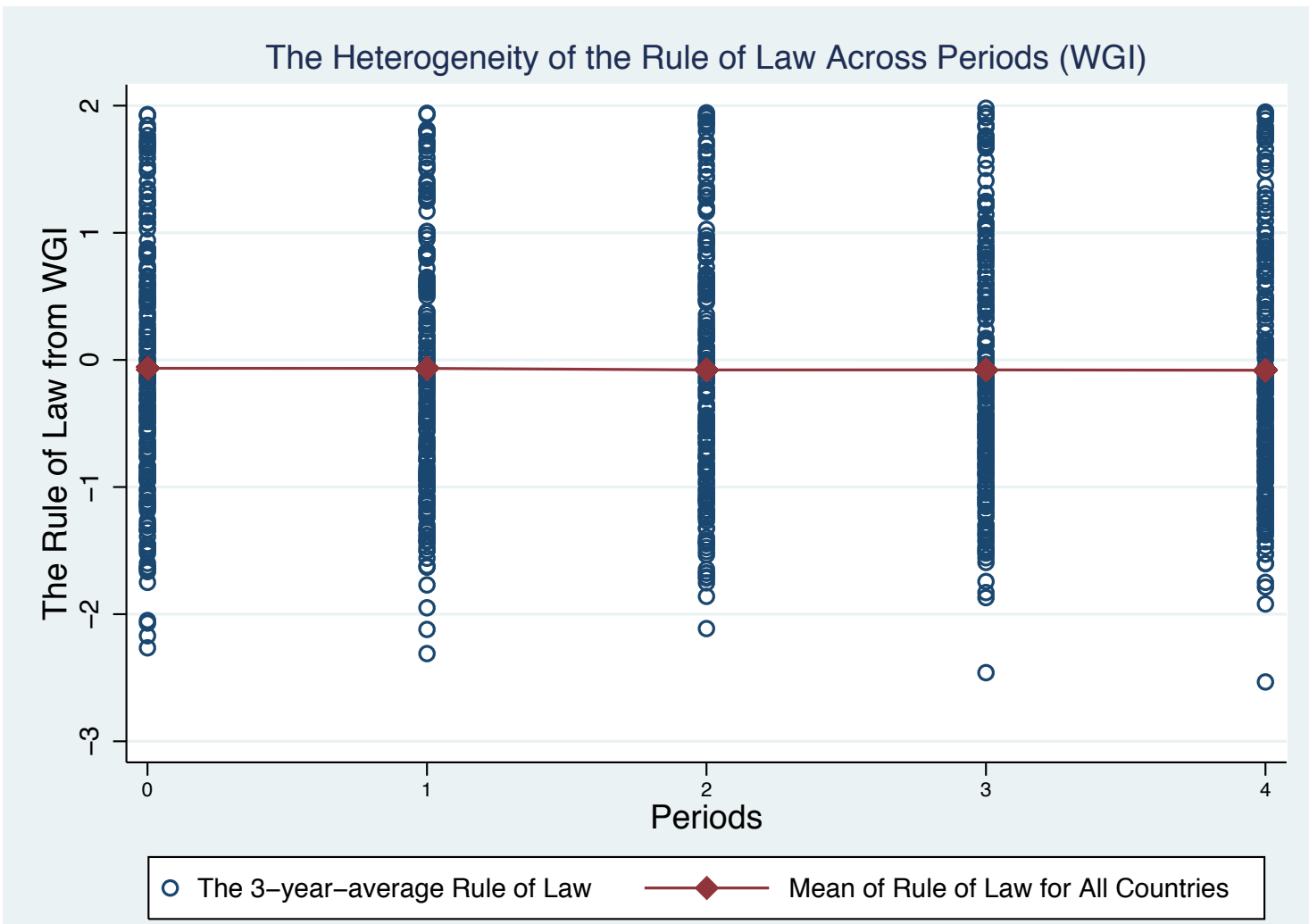


Figure 2.6: The Heterogeneity of the Rule of Law Across Periods (ICRG)

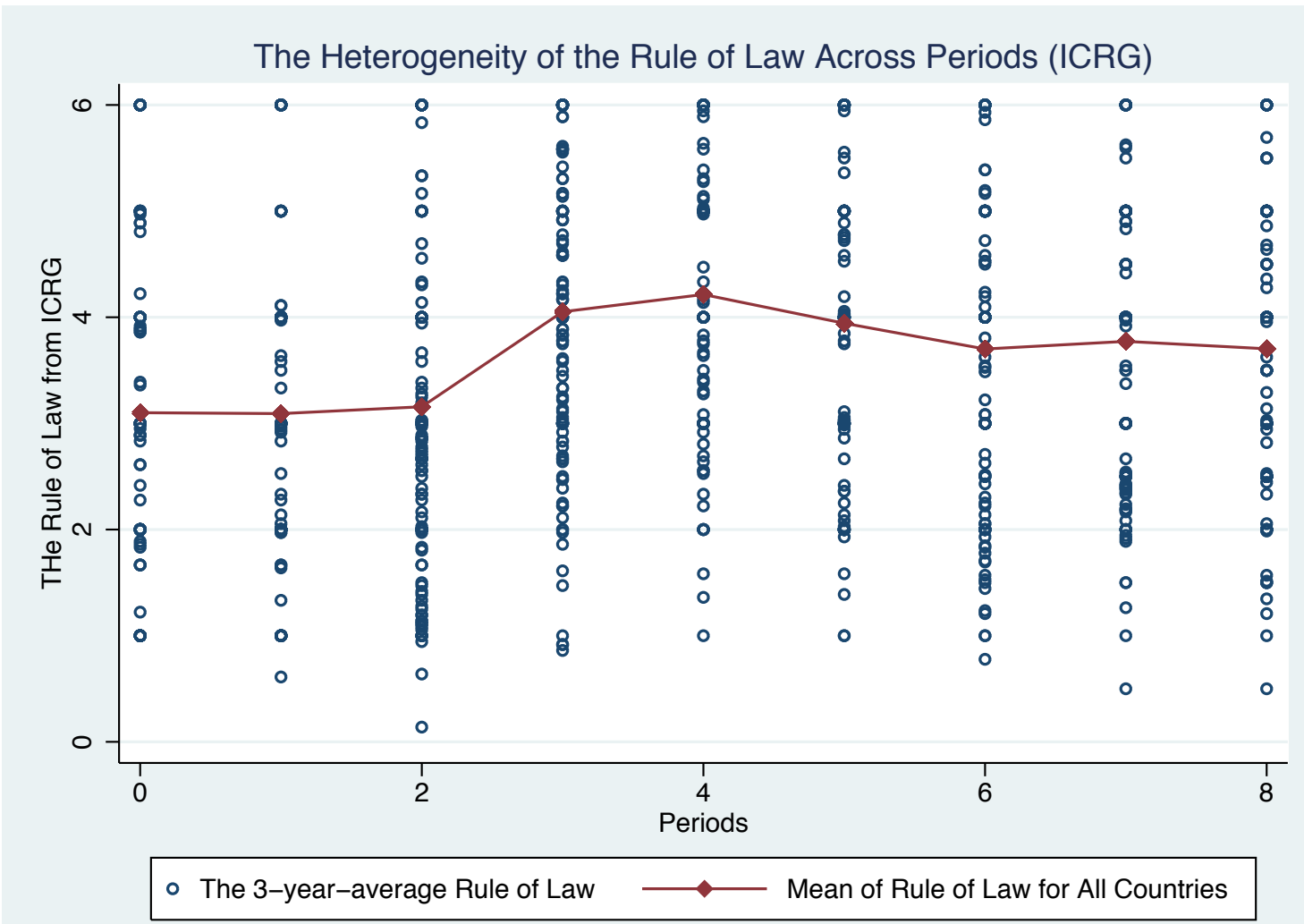




\section{CHAPTER 3 \\ NOTES ON GLOBALIZATION, GROWTH, AND RELATIVE \\ CONSUMPTION}

\subsection{Introduction}

Recently there has been a revival of interest in the "keeping up with the Joneses" phenomenon in the economics literature. This is mostly because a number of studies have found strong evidence in support of the phenomenon. As a result, there has also been a number of theoretical papers exploring its implications for various areas in economics. In what follows I construct a dynamic general equilibrium model of international keeping up with the Joneses to investigate the growth implications of such behavior by economic agents.

The observation that economic agents care about their consumption or income levels not only in an absolute sense, but relative to a community of their peers goes back to at least Adam Smith who defined "necessaries" as "not only the commodities which are indispensably necessary for the support of life, but whatever the custom of the country renders it indecent for creditable people, even of the lowest order, to be without. A linen shirt, for example, is, strictly speaking, not a necessary of life. The Greeks and Romans lived, I suppose, very comfortably, though they had no linen. But in the present times, . . . a creditable day-labourer would be ashamed to appear in public without a linen shirt." Veblen commented on the phenomenon in 1899 suggesting that "the accepted standard of expenditure in the community or in the class to which a person belongs largely determines what his standard of living will be. It does this directly by commending itself to his common sense as right and good, through his habitually contemplating it and assimilating the scheme of life in which it belongs; but it does so also indirectly 
through popular insistence on conformity to the accepted scale of expenditure as a matter of propriety, under pain of disesteem and ostracism." Duesenberry's relative income hypothesis, emphasizing that households derive utility from income relative to their peers, has recently been revived by the "happiness" literature reviewed by Clark et al. (2008) who emphasize the connection between Duesenberry's work and the new empirical happiness literature that tries to explain the Easterlin paradox, the observation that economic growth that raises incomes overall does not lead to higher levels of "happiness" over time in surveys and other puzzles. ${ }^{1}$ There is, however, also a large and growing empirical literature that relies on cross-section data suggesting that income does raise happiness. A key challenge for the happiness literature has, therefore, been to render consistent the findings from cross-section data (suggesting a positive income and happiness correlation) with those from timeseries data (suggesting no correlation between income and happines). The current consensus in the literature focuses on relative income and consumption as the answer to the puzzle, suggesting that individuals derive utility not only from absolute levels of consumption but also from consumption relative to others. That this may indeed be the case finds strong empirical support from cross-sectional studies (such as that of Di Tella et al. (2003), Blanchflower and Oswald (2004), and Ferrer-i-Carbonell (2005)) as well as experimental work (see, for instance, Solnick and Hemenway (1998), Johansson-Stenmann (2002), and Alpizar et al. (2005)).

There is now also a growing theoretical literature on the implications of incorporating relative (consumtion or income) status concerns for long-run economic growth. Cole et al. (1992) look at a matching model and endogenize concern for relative status in a model of long-run growth. Carroll et al. (1997) introduce con-

\footnotetext{
${ }^{1}$ For the "happiness" literature, see, among others, Easterlin $(1974,1995)$, Kahnemann and Krueger (2006), and Layard (2005).
} 
cern for one's consumption relative to one's own past consumption and relative to others' current consumption into an endogenous AK-type growth model. ${ }^{2}$ The model I present below deviates from the models mentioned so far in three important respects. First here, unlike the previous theoretical papers that confine to their attention to closed economies, I explore the implications of concern for relative status in an open economy setting that involves two large open economies. Second, given this setting, a meaningful steady-state equilibrium fails to exist if I assume, like the rest of the literature, constant rates of time preference. This is because, as is well-known, if the constant rates of time preference are assumed to be different, the economy that has the higher rate asymptotically becomes negligibly small. If they are assumed to be equal the two economies end up being clones of each other with no economically meaningful difference between them. To avoid these outcomes, in sharp contrast to existing literature, I endogenize the rates of time preference. Third, I focus on a case of comparison utility so far ignored in the literature: my model different types of agents comparing their consumption levels to that of different reference groups. Specifically, I postulate that relatively "rich" agents derive utility from their consumption relative to the consumption of other "rich" agents agents in the world, while "poor" agents compare their consumption to the average domestic consumption. This focus is motivated by the observation that the elite in any given country tend to be more cosmopolitan in their outlook having the means to travel, communicate, and interact with their peers globally, whereas the "poor" agents lacking the means to do so tend to be culturally less international.

\footnotetext{
${ }^{2}$ Other noteworthy recent growth models that introduce relative status include Fisher and Hof (2000), Cooper, Garca-Pealosa and Funk (2001), and Liu and Turnovsky (2005).
} 


\subsection{Autarkic Equilibrium}

Consider an autarkic economy in which two types of households produce a single, homogeneous output, using a uniform technology and stocks of reproducible inputs,

$$
Q_{i}(t)=\rho K_{i}(t), i=1,2
$$

where $Q_{i}$ denotes flows of output, $K_{i}$ are stocks of inputs accumulated from past output, and $\rho$ a fixed output-input coefficient that also denotes the rate of reurn to the inputs. I start here with the autarkic equilibrium in a bare-bones model that does not have adjustment costs in investment. In the open economy version to follow this implies that physical capital can instantaneously and freely move across countries.

The domestic consumption status or relative consumption $c$ of the representative domestic household is defined by

$$
c(t) \equiv \frac{C(t)}{C^{a}(t)},
$$

where $C(t)$ is his consumption level at $t$, given that he perceives average consumption to be $C^{a}$. For the autarkic economy I will suppose that $C^{a}=(1-n) C_{1}+n C_{2}$. Here, a fraction, $1-n$, of the households are type- 1 and they differ from type- 2 households in that the latter attach greater weight to utility from relative consumption.

The agents under consideration maximize lifetime utility, which is the discounted sum of instantaneous felicities. An increase in felicity has two possible sources: It may be due to a rise in consumption status $c$ at a given level of consumption $C$, or it may result from growth in $C$ at given $c$. Thus,

$$
\tilde{V}[\Gamma(0)] \equiv \int_{0}^{\infty} v[C(t), c(t)] \exp \left\{-\int_{0}^{\infty} \tilde{\theta}[C(s), c(s) ; \omega] d s\right\} d t, v_{i}>0(i=1,2)
$$


where $\Gamma(0) \equiv\{C(t), c(t)\}_{t=0}^{\infty}$ denotes the expected path of $C$ and $c$ starting at $t=0$; $v[\cdot]$ felicity from $C(t)$ and $c(t)$; and $\tilde{\theta}[\cdot]$ a variable discount rate that depends on the shift parameter $\omega$, which measures the degree of the household impatience. It is convenient to follow Epstein and Hynes (1983) and specialize (3.3) to

$$
V[\Gamma(0)] \equiv \int_{0}^{\infty}-\exp \left\{-\int_{0}^{\infty} \tilde{\theta}[C(s), c(s) ; \omega] d s\right\} d t
$$

by setting $v(C, c)=-1 .^{3}$ I further specialize (3.3) by assuming that the discount rate $\tilde{\theta}[\cdot]$ is (i) separable in utility from $C$ and $c$; (ii) increasing in both of these arguments: ${ }^{4}$

$$
\begin{gathered}
\tilde{\theta}[C(s), c(s) ; \omega] \equiv \omega+\varphi[c(s)]+u[C(s)], u^{\prime}, \varphi^{\prime}>0, u^{\prime \prime}, \varphi^{\prime \prime}<0, \\
\tilde{\theta}_{i}>0(i=1-3)
\end{gathered}
$$

Finally, following a suggestion of Obstfeld (1990), I assume that $u[C(t)]$ has an upper bound $\delta$ : as $C(t) \rightarrow \infty, u[C(t)] \rightarrow \delta<\infty$. Consequently, though in a setting of endogenous growth the level of consumption $C$ will increase without bound, the discount rate need not become unbounded, if relative consumption $c$ stabilizes. Since $u[C(t)]$ equals the constant $\delta$ in the neighborhood of a corresponding steady state, the intertemporal decision problem can now be viewed as locally reducing to the maximization of

$$
J[\Gamma(0)] \equiv \int_{0}^{\infty}-\exp \left\{-\int_{0}^{\infty} \tilde{\theta}[c(s) ; \omega] d s\right\} d t, \tilde{\theta}_{i}>0(i=1-3), \tilde{\theta}_{i 1}<0,
$$

${ }^{3}(3.4)$ preserves the essential properties of (3.3) and yields a particularly simple form of momentary time preference, dependent on $\Gamma(t)$ alone and not on $C(t)$ and $c(t)$.

${ }^{4}$ Which should be compared to the standard assumption [Uzawa (1968)] that $\tilde{\theta}[\cdot]$ is increasing in $C$ alone. 
from (3.4) and (3.5). It is convenient to suppose that both $u$ and $\varphi$ in (3.5) take logarithmic forms, so that the discount rate in (3.6) becomes

$$
\theta_{i}=\omega_{i}+\left(1-\beta_{i}\right) \ln C_{i}+\beta_{i} \ln c_{i}=\omega_{i}+\left(1-\beta_{i}\right) \delta+\beta_{i} \ln c_{i} i=1,2
$$

where $\beta_{i}$ is the weight attached by domestic households to utility from relative consumption. As type-2 households attach greater weight to utility from relative consumption $\beta_{1}<\beta_{2}$. Note that $\omega$ represents a status-impatience parameter.

When the mass of households is normalized to one, one can use $C^{a}=(1-n) C_{1}+$ $n C_{2}$ to obtain relative consumptions $c_{i}=C / C^{a}$

$$
1=(1-n) c_{1}+n c_{2}
$$

The optimization problem of a representative domestic household may now be summarized. His task is to find a path $\Gamma(0)$ that maximizes

$$
J[\Gamma(0)] \equiv \int_{0}^{\infty}-\exp [-z(t)] \exp \left[-\int_{0}^{t} \rho(s) d s\right] d t
$$

subject to

$$
\begin{gathered}
\dot{z}(t)=\theta[c(t)]-\rho(t) \\
\dot{k}(t)=\left[\rho(t)-g^{a}(t)\right] k(t)-c(t), k(0)>0, \\
k(t) \equiv K(t) / C^{a}(t), g^{a}(t) \equiv \dot{C}^{a}(t) / C^{a}(t),
\end{gathered}
$$

where $\left\{g^{a}(t)\right\}_{t=0}^{\infty}$ and $\{\rho(t)\}_{t=0}^{\infty}$ denote the path of the growth rate $g^{a}$ of average world consumption and the path of the numeraire interest rate $\rho$ expected by domestic agents.

The first-order necessary conditions (where $\lambda \equiv \tilde{\lambda} \exp (z), \phi \equiv \tilde{\phi} \exp (z))$

$$
\frac{-\phi}{c}=\varsigma
$$




$$
\begin{gathered}
\dot{\varsigma}=\varsigma\left[\theta(c)-\left(\rho-g^{a}\right)\right] \\
\dot{\phi}=\phi \theta(c)+1 .
\end{gathered}
$$

This setup gives rise to the momentary rate of time preference

$$
\Omega(\phi)=\theta(c)\left\{1-\frac{\phi+[\theta(c)]^{-1}}{\phi}\right\}=-\phi^{-1}
$$

where $\phi$, the solution of (3.14) for convergent $\phi$, equals the utility value $J[\Gamma(t)]$ of a stream of future consumption $\Gamma(t)$ starting at $t$.

By combining (3.15) with (3.12)-(3.14), one finds the law of optimal relative consumption for a given representative domestic household to be

$$
\dot{c}=c\left[\rho-g^{a}-\Omega(\phi)\right] .
$$

Using the definition of $C^{a}$ and $g^{a}$ I obtain

$$
(1-n) c_{1} g_{1}+n c_{2} g_{2}=g^{a}
$$

The $g_{i}$ are determined by

$$
g_{i}=\rho-\Omega\left(\phi_{i}\right)
$$

from (3.16) and the definition of $c_{i}$.

Using (3.17) and (3.18) in (3.16) one finds

$$
\begin{gathered}
\dot{c}_{1}=c_{1} c_{2} n\left[\Omega_{2}\left(\phi_{2}\right)-\Omega_{1}\left(\phi_{1}\right)\right] \\
\dot{c}_{2}=c_{2} c_{1}(1-n)\left[\Omega_{1}\left(\phi_{1}\right)-\Omega_{2}\left(\phi_{2}\right)\right]
\end{gathered}
$$

which represent the law of motion of the distribution of consumption. From (3.14) I obtain

$$
\dot{\phi}_{i}=\phi_{i} \theta_{i}\left(c_{i}\right)+1 \equiv \zeta(\phi, c), \zeta_{1}>0, \zeta_{2}<0
$$


which, together with (3.19), form a self-contained system in the three non-predetermined state variables $\phi_{i}$ and $c_{1}$.

Clearance of the output market requires that total output in this economy equal total consumption and investment

$$
\rho K^{a}=C^{a}+\dot{K}^{a}, K^{a}=\Sigma_{i} K_{i}
$$

Using equations (3.17) and (3.22) together with the definition $\gamma \equiv C^{a} / K^{a}$ yields

$$
\dot{\gamma}=\gamma\left(\gamma-\Omega^{a}\right), \Omega^{a} \equiv(1-n) c_{1} \Omega_{1}+n c_{2} \Omega_{2}
$$

Finally, the law of motion for the distribution of wealth, $f_{1} \equiv K_{1} / K^{a}$, is obtained from equations (3.11) and (3.22) as

$$
\dot{f}_{1}=\gamma\left(f_{1}-c_{1}\right)
$$

Equations (3.19), (3.21), (3.23), and (3.24) constitute a five-dimensional differential equation system with four jumping and one $(f)$ pre-determined variable. It is straightforward to show that the linearized version of this system possesses one negative and four positive eigenvalues, guaranteeing local saddlepath stability. Decentralized optimization ensures that the economy converges to a steady-state, whose properties are easily derived. First, (3.15) and $\dot{\phi}_{i}=0$ imply

$$
\bar{\Omega}_{1}=\bar{\theta}\left(c_{1} ; \beta_{1}\right)=\bar{\theta}\left(c_{2} ; \beta_{2}\right)=\bar{\Omega}_{2} .
$$

Thus, assuming $\omega_{1}=\omega_{2}=\omega$ I have

$$
\bar{\Omega}=\omega+\left(1-\beta_{1}\right) \delta+\beta_{1} \ln c_{1}=\omega+\left(1-\beta_{2}\right) \delta+\beta_{2} \ln c_{2} .
$$

It is straightforward to show that $\beta_{2}>\beta_{1} \Rightarrow c_{1}<c_{2}$ at the steady-state equilibrium. Since from (3.24) I have $\bar{f}_{1}=\bar{c}_{1}$, from the definition of $f_{1}$, it follows that $\bar{f}_{2}=\bar{c}_{2}$. 
Thus, type-2 agents, that are more concerned with relative consumption, will also own a relatively larger share of the capital stock in the long run.

In what follows I would like to explore the effects of opening up countries with different types of households to intertemporal trade. For this purpose it is important to determine how differences in household types give rise to differences in autarkic rates of time preference at the steady state. The most parsimonious way of studying the issue is to suppose that the world consists of two countries each of which is inhabited by two types of households. The countries are then assumed to differ only with respect to the degree to which, say, type-1 households value utility from relative consumption. Suppose now, without loss of generality that $\beta_{1}<\beta_{1}^{*}$ (where asterisks indicate foreign country variables). Again it is straighforward to show that the country with the higher $\beta_{1}$ would, ceteris paribus, have a lower autarkic rate of time preference, i.e. $\beta_{1}<\beta_{1}^{*} \Rightarrow \bar{\Omega}>\bar{\Omega}^{*}$

As both countries have access to the same linear $A K$ technology with production functions given by $Q^{(*)}=\rho K_{i}^{(*)}$ their autarkic growth rates would then be given by

$$
\rho-\bar{\Omega}^{*}=\bar{g}^{*}<\bar{g}=\rho-\bar{\Omega} .
$$

Thus, the economy in which poor agents care more about relative consumption will grow slower in the autarkic steady-state equilibrium.

\subsection{Global Equilibrium}

I will now open these countries up in two senses of the term: (i) liberalize trade, and (ii) allow international comparisons of relative consumption. Here liberalizing either intratemporal (goods) or intertemporal (international borrowing or lending) trade does not generate any trade for the simple reason that (a) there is only one good and (b) rates of return, $\rho$, on assets are already equalized. Thus, the only 
effect of globalization (opening up) is to globalize the comparison groups by which relative levels of consumption are judged. I will consider two cases below depending on the comparison groups.

\subsubsection{Comparison group: Global average}

Here each agent in each country derives utility from her consumption relative to the world average.

Suppose that both countries have their populations normalized to unity. I can write average world consumption, $c^{\text {aver }}$, as

$$
c^{\text {aver }}=(1 / 2)\left[(1-n) C_{1}+\left(1-n^{*}\right) C_{1}^{*}+n C_{2}+n * C_{2}^{*}\right]
$$

Relative consumptions $c_{i}^{(*)}$ as perceived by agents would then be given by

$$
c_{i}^{(*)} \equiv \frac{C_{i}^{(*)}}{c^{\text {aver }}} .
$$

At a steady state where $\bar{\theta}_{1}=\bar{\theta}_{2}=\bar{\theta}_{1}^{*}=\bar{\theta}_{2}^{*}$, I have $\bar{c}_{i}=\bar{c}_{i}^{*}$ for $i=1,2$. From (3.27) this implies that

$$
\left[1-\frac{\left(n+n^{*}\right)}{2}\right] \bar{c}_{1}+\frac{\left(n+n^{*}\right)}{2} \bar{c}_{2}=1 .
$$

Using (3.8), (3.28), $n^{*}<n$, and Figure 2, it is now straightforward to show that "globalization" equalizes the rates of growth by equalizing the rates of time preference:

$$
a-\bar{\Omega}^{*}=\bar{g}^{*}<g^{W}=a-\bar{\Omega}^{W}<\bar{g}=a-\bar{\Omega}
$$

where the superscript $W$ denotes the values of the variables in the open economy setup.

Thus, globalization raises the long-run growth rate of the slower-growing foreign economy and vice versa for the domestic one. 


\subsubsection{Comparison group: Domestic rich vs foreign rich}

Here I suppose that globalization implies that the domestic rich (type-2 agents) compare their consumption to foreign rich (and vice versa) so that the relevant relative consumption levels are

$$
c_{2}=\frac{C_{2}}{C_{2}^{w, a v e r}}=\frac{C_{2}}{\frac{n C_{2}+n^{*} C_{2}^{*}}{n+n^{*}}}
$$

where $C_{2}^{w, a v e r}$ denotes the world average of type- 2 household consumption levels. The relative wealth levels of type- 2 agents need consequently be redefined as

$$
f_{2}=\frac{K_{2}}{K_{2}^{w, a v e r}}=\frac{K_{2}}{\frac{n K_{2}+n^{*} K_{2}^{*}}{n+n^{*}}}
$$

I still have type-1 households comparing their consumption to type-2 households. Thus

$$
c_{1}=\frac{C_{1}}{C^{\text {aver }}}=\frac{C_{1}}{(1-n) C_{1}+n C_{2}} .
$$

In the rest of the paper, I am interested in looking at the effects of "globalization" on welfare and the distribution of wealth and income when the comparison group of the wealthy everywhere is their foreign counterparts. Since this requires looking at the full adjustment paths of the relevant variables, I now turn to the solution of the differential equation system.

\section{Laws of motion for the subjective relative preferences}

At a point in time, as in the autarkic case, the behavior of households in any given economy are defined by the solution of the lifetime utility maximization problem (3.9) subject to (3.10) and (3.11) with the difference that relative consumption levels here are given by (3.29) and (3.31). The solution of the problem yields in addition to (3.21) the laws of motion of relative consumptions $c_{i}$, consumption-wealth ratios $\gamma_{i}$, and relative wealth levels $f_{i}$ as 


$$
\begin{gathered}
\dot{c}_{i t}^{(*)}=c_{i}^{(*)}\left(\Omega_{i}^{a(*)}-\Omega_{i}^{(*)}\right) \\
\Omega_{1}^{a(*)} \equiv(1-n)^{(*)} c_{1}^{(*)} \Omega_{1}^{(*)}+\left[1-\left(1-n^{(*)}\right) c_{1}^{(*)}\right] \Omega_{2}^{(*)} \\
\Omega_{2}^{a} \equiv \frac{n}{n+n^{*}} c_{2} \Omega_{2}+\left(1-\frac{n}{n+n^{*}} c_{2}\right) \Omega_{2}^{*} \\
\dot{\gamma}_{i t}=\gamma_{i}\left(\gamma_{i}-\Omega_{i}^{a}\right), i=1,2 \\
\dot{f}_{i t}=\gamma_{i}\left(f_{i}-c_{i}\right)
\end{gathered}
$$

where $\gamma_{i} \equiv C_{i}^{a v} / K_{i}^{a v}, f_{i} \equiv K_{i} / K_{i}^{a v}$ and $K_{1}^{a v} \equiv(1-n) K_{1}+n K_{2}, K_{2}^{a v} \equiv\left(n K_{2}+\right.$ $\left.n^{*} K_{2}^{*}\right) /\left(n+n^{*}\right)$ and $n+n^{*}=n c_{2}+n^{*} c_{2}^{*}$.

These equations constitute a thirteen-dimensional differential equation system with ten jumping and three $\left(f_{i}\right)$ pre-determined variables. It is straightforward to show that the linearized version of this system possesses three negative and ten positive eigenvalues, guaranteeing local saddlepath stability.

\section{Steady State}

Suppose now that the two countries differ in only one respect: foreign type- 1 households attach greater weight to utility from relative consumption, $\beta_{1}<\beta_{1}^{*}<\beta_{2}=\beta_{2}^{*}$. At an autarkic steady state this implies that

$$
\bar{c}_{1}^{\text {aut }}<\bar{c}_{1}^{* a u t}, \bar{c}_{2}^{\text {aut }}>\bar{c}_{2}^{* a u t .} \Rightarrow \bar{\Omega}^{\text {aut }}>\bar{\Omega}^{* a u t} .
$$

At a steady state under globalization, where $\bar{\theta}_{2}=\bar{\theta}_{2}^{*}$, I have $C_{2}=C_{2}^{*}$ and, thus, $\bar{c}_{2}=\bar{c}_{2}^{*}=1$. Since the last two equalities imply $\bar{c}_{2}^{(*)}<\bar{c}_{2}^{(*), a u t}$ and $\bar{c}_{1}^{(*)}<\bar{c}_{1}^{(*), a u t} \mathrm{I}$ have the following ${ }^{5}$

$$
\bar{\Omega}^{(*)}<\bar{\Omega}^{(*), a u t} \Rightarrow \bar{g}^{(*)}>\bar{g}^{(*), a u t} .
$$

\footnotetext{
${ }^{5}$ Note that I do not need to refer to the type-1 households to derive the results concerning growth. The equality of their rates of time preference to those of type- 2 households at a steady state is used to determine their relative consumption levels.
} 
That is, across steady states globalization increases the rate of growth of both countries above their autarkic levels.

To explore the effects of globalization in this world on welfare and the distribution of wealth I now turn to the differential equations themselves and their solutions.

\section{Solutions of subjective model differential equations}

Linearizing the model yields the following set of solutions for the differential equations.

$$
\begin{aligned}
& \phi_{1 t}-\bar{\phi}_{1}=\frac{\beta_{1} \beta_{2}\left(f_{20}-\bar{f}_{2}\right)\left[1-\bar{c}_{1}(1-n)\right]}{\bar{\Omega}^{2}\left[\beta_{1}\left[1-\bar{c}_{1}(1-n)\right]-\beta_{2}\right]}\left[\exp \left(\lambda_{2} t\right)-\exp \left(\lambda_{1} t\right)\right]+\frac{\beta_{1}\left(f_{10}-\bar{f}_{1}\right)}{\bar{c}_{1} \bar{\Omega}^{2}} \exp \left(\lambda_{1} t\right) \\
& \phi_{2 t}-\bar{\phi}_{2}=\frac{\beta_{2}\left(f_{20}-\bar{f}_{2}\right)}{\bar{\Omega}^{2}} \exp \left(\lambda_{2} t\right) \\
& \phi_{1 t}^{*}-\bar{\phi}_{1}^{*}=\frac{\beta_{1}^{*} \beta_{2}\left(f_{20}-\bar{f}_{2}\right)\left[1-\bar{c}_{1}^{*}\left(1-n^{*}\right)\right]}{\bar{\Omega}^{2}\left[\beta_{1}^{*}\left[1-\bar{c}_{1}^{*}\left(1-n^{*}\right)\right]-\beta_{2}\right]}\left[\exp \left(\lambda_{3} t\right)-\exp \left(\lambda_{2} t\right)\right]+\frac{\beta_{1}^{*}\left(f_{10}^{*}-\bar{f}_{1}^{*}\right)}{\bar{c}_{1}^{*} \bar{\Omega}^{2}} \exp \left(\lambda_{3} t\right) \\
& \phi_{2 t}^{*}-\bar{\phi}_{2}^{*}=-\frac{\beta_{2}\left(f_{20}-\bar{f}_{2}\right)}{\bar{\Omega}^{2}} \exp \left(\lambda_{2} t\right) \\
& c_{1 t}-\bar{c}_{1}=\frac{\bar{c}_{1} \beta_{2}\left(f_{20}-\bar{f}_{2}\right)\left[1-\bar{c}_{1}(1-n)\right]}{\bar{\Omega}\left[\beta_{1}\left[1-\bar{c}_{1}(1-n)\right]-\beta_{2}\right]}\left[\left(\bar{\Omega}-\lambda_{2}\right) \exp \left(\lambda_{2} t\right)-\left(\bar{\Omega}-\lambda_{1}\right) \exp \left(\lambda_{1} t\right)\right] \\
& +\frac{\left(\bar{\Omega}-\lambda_{1}\right)\left(f_{10}-\bar{f}_{1}\right)}{\bar{\Omega}} \exp \left(\lambda_{1} t\right) \\
& c_{2 t}-\bar{c}_{2}=\frac{\left(f_{20}-\bar{f}_{2}\right)\left(\bar{\Omega}-\lambda_{2}\right)}{\bar{\Omega}} \exp \left(\lambda_{2} t\right) \\
& c_{1 t}^{*}-\bar{c}_{1}^{*}=\frac{\bar{c}_{1}^{*} \beta_{2}\left(f_{20}-\bar{f}_{2}\right)\left[1-\bar{c}_{1}^{*}\left(1-n^{*}\right)\right]}{\bar{\Omega}\left[\beta_{1}^{*}\left[1-\bar{c}_{1}^{*}\left(1-n^{*}\right)\right]-\beta_{2}\right]}\left[\left(\bar{\Omega}-\lambda_{3}\right) \exp \left(\lambda_{3} t\right)-\left(\bar{\Omega}-\lambda_{2}\right) \exp \left(\lambda_{2} t\right)\right] \\
& +\frac{\left(\bar{\Omega}-\lambda_{3}\right)\left(f_{10}^{*}-\bar{f}_{1}^{*}\right)}{\bar{\Omega}} \exp \left(\lambda_{3} t\right) \\
& c_{2 t}^{*}-\bar{c}_{2}^{*}=1+\frac{n}{n^{*}}\left(1-c_{2 t}\right)-\bar{c}_{2}^{*} \\
& f_{1 t}-\bar{f}_{1}=\frac{\bar{c}_{1} \beta_{2}\left(f_{20}-\bar{f}_{2}\right)\left[1-\bar{c}_{1}(1-n)\right]}{\left[\beta_{1}\left[1-\bar{c}_{1}(1-n)\right]-\beta_{2}\right]}\left[\exp \left(\lambda_{2} t\right)-\exp \left(\lambda_{1} t\right)\right]+\left(f_{10}-\bar{f}_{1}\right) \exp \left(\lambda_{1} t\right)
\end{aligned}
$$




$$
\begin{aligned}
& f_{2 t}-\bar{f}_{2}=\left(f_{20}-\bar{f}_{2}\right) \exp \left(\lambda_{2} t\right) \\
& f_{1 t}^{*}-\bar{f}_{1}^{*}=\frac{\bar{c}_{1}^{*} \beta_{2}\left(f_{20}-\bar{f}_{2}\right)\left[1-\bar{c}_{1}^{*}\left(1-n^{*}\right)\right]}{\left[\beta_{1}^{*}\left[1-\bar{c}_{1}^{*}\left(1-n^{*}\right)\right]-\beta_{2}\right]}\left[\exp \left(\lambda_{3} t\right)-\exp \left(\lambda_{2} t\right)\right]+\left(f_{10}^{*}-\bar{f}_{1}^{*}\right) \exp \left(\lambda_{3} t\right) \\
& f_{2 t}^{*}-\bar{f}_{2}^{*}=1+\frac{n}{n^{*}}\left(1-f_{2 t}\right)-\bar{f}_{2}^{*} \\
& \gamma_{1 t}-\bar{\gamma}_{1}=\frac{-\beta_{2} \bar{\Omega}\left(f_{20}-\bar{f}_{2}\right)\left[1-\bar{c}_{1}(1-n)\right]}{\left[\beta_{1}\left[1-\bar{c}_{1}(1-n)\right]-\beta_{2}\right]}\left[\frac{\left(\beta_{2}-\beta_{1}\right)}{\left(\bar{\Omega}-\lambda_{2}\right)} \exp \left(\lambda_{2} t\right)+\frac{\beta_{1}(1-n) \bar{c}_{1}}{\left(\bar{\Omega}-\lambda_{2}\right)} \exp \left(\lambda_{1} t\right)\right] \\
& +\left(f_{10}-\bar{f}_{1}\right) \frac{\bar{\Omega} \beta_{1}(1-n)}{\left(\bar{\Omega}-\lambda_{1}\right)} \exp \left(\lambda_{1} t\right) \\
& \gamma_{2 t}-\bar{\gamma}_{2}=0 \\
& \gamma_{1 t}^{*}-\bar{\gamma}_{1}^{*}=\frac{\beta_{2} \bar{\Omega}\left(f_{20}-\bar{f}_{2}\right)\left[1-\bar{c}_{1}^{*}\left(1-n^{*}\right)\right]}{\left[\beta_{1}^{*}\left[1-\bar{c}_{1}^{*}\left(1-n^{*}\right)\right]-\beta_{2}\right]}\left[\frac{\left(\beta_{2}-\beta_{1}^{*}\right)}{\left(\bar{\Omega}-\lambda_{2}\right)} \exp \left(\lambda_{2} t\right)+\frac{\beta_{1}^{*}\left(1-n^{*}\right) \bar{c}_{1}^{*}}{\left(\bar{\Omega}-\lambda_{3}\right)} \exp \left(\lambda_{3} t\right)\right] \\
& +\left(f_{10}^{*}-\bar{f}_{1}^{*}\right) \frac{\bar{\Omega} \beta_{1}\left(1-n^{*}\right)}{\left(\bar{\Omega}-\lambda_{3}\right)} \exp \left(\lambda_{3} t\right) \\
& \gamma_{2 t}^{*}=\gamma_{2 t}
\end{aligned}
$$

Here an important point to note is that the definition of both relative consumption, $c$, and relative wealth, $f$, changes for type-2 agents as the autarkic economies are opened up. This change in the perspective of type- 2 agents requires that at $t=0$, I write

$$
f_{20}=\frac{K_{20}}{K_{20}^{w, a v e r}}=\frac{K_{20}}{\frac{n K_{20}+n^{*} K_{20}^{*}}{n+n^{*}}}=\frac{\mu_{0}}{\frac{n \mu_{o}+n^{*}}{n+n^{*}}}
$$

where $\mu_{0} \equiv K_{20} / K_{20}^{*}$ denotes the wealth of domestic type-2 agents relative to their foreign counterparts at $t=0$. The value of $\mu_{0}$ is historically determined by the initial values of the wealth of these agents and their growth rates during autarky. In my simulations below I report the results using two possible values of $\mu_{0}$ corresponding to the cases of domestic agents being relatively more and less wealth compared to their foreign counterparts. 
The negative eigenvalues are given by

$$
\begin{gathered}
\lambda_{1}=\frac{1}{2}\left(\Omega-\sqrt{\Omega} \sqrt{\Omega+4 \beta_{1}\left[1-c_{1}(1-n)\right]}\right) \\
\lambda_{2}=\frac{1}{2}\left(\Omega-\sqrt{\Omega} \sqrt{\Omega+4 \beta_{2}}\right) \\
\lambda_{3}=\frac{1}{2}\left(\Omega-\sqrt{\Omega} \sqrt{\Omega+4 \beta_{1}^{*}\left[1-c_{1}^{*}\left(1-n^{*}\right)\right]}\right) .
\end{gathered}
$$

A number of results immediately follow from the analytical solutions before I turn to the calibration and simulation of the model. First, note that whether an agent suffers a welfare loss or benefits from a welfare gain upon globalization can be determined in a straightforward way by the sign of $\phi_{i 0}^{+}-\bar{\phi}_{i 0}$. This is because $\phi_{i 0}$ is by definition simply the present discounted value of lifetime utility at $t=0$. Thus, suppose that globalization is unexpectedly introduced at $t=0$. The forward-looking jumping variable $\phi$ will instantaneously and discretely change upon impact (attaining the value $\bar{\phi}_{i 0}^{+}$), with the change in its $t=0$ value measuring the impact of globalization on the welfare of the agent in question. Thus, for instance, globalization would change the welfare of a type- 1 domestic agent by $\phi_{10}^{+}-\bar{\phi}_{10}^{-}=\frac{\beta_{1}\left(f_{10}-f_{1}\right)}{c_{1} \Omega^{2}}+\left(\bar{\phi}_{1}-\bar{\phi}_{10}\right)$. As $-1 / \bar{\phi}_{10}^{-}=\bar{\Omega}^{\text {aut }}>\bar{\Omega}=-1 / \bar{\phi}_{1}$, the second term on the right, $\left(\bar{\phi}_{1}-\bar{\phi}_{10}\right)<0$, that is the welfare of type-1 domestic agents is lower in the long-run under globalization. To determine whether the agent would gain from globalization, however, requires the calculation of the discounted utility from the entire transition path between the two long-run equilibria and not just a comparison of the latter two. This is achieved by determining the sign of $\phi_{10}^{+}-\bar{\phi}_{10}^{-}$, which includes the additional term $\frac{\beta_{1}\left(f_{10}-f_{1}\right)}{c_{1} \Omega^{2}}$. Thus, for this agent to gain from globalization this last term needs to be positive and large enough. Intuitively speaking, this, in turn requires $f_{10}>f_{1}$, i.e. globalization should trigger a sufficiently large reduction in the type-1 agent's share of wealth. In other words, globalization should induce a decrease in savings and an increase in consumption to yield welfare gains. To determine such changes I calibrate and 
simulate the model and obtain the impulse-response functions displayed in Figure 3.1, Figure 3.2 and Figure 3.3.

My main results can now be noted as follows. Along the transition path, domestic type-1 households reduce their relative holdings of wealth, which allows them to increase their relative consumption initially. However, the temporary increase in consumption is not suffiecient to compensate for the long-run loss in their welfare and, as a result, domestic type-1 households suffer a loss of welfare under globalization. Their foreign type-1 counterparts, however, do not have to reduce their consumption in the later stages of their adjustment to the extent domestic agents need to do, and as a result, gain from globalization. Type-2 domestic households gain from globalization if their initial wealth levels relative to their foreign counterparts are higher; they lose otherwise. Intuitively, if these households have lower initial wealth relative to their foreign counterparts, they have to save more and consume less "to keep up with the Joneses," which reduces their welfare. To the extent that they are ahead of their foreign counterparts they enjoy their relative consumption status and they gain from globalization. Similar reasoning explains the changes in the welfare of foreign type-2 households reported in the figure.

\subsection{Conclusion}

In this chapter, my focus is the welfare and distributional consequences of the household concern for international relative status or "keeping up with the Joneses." The empirical literature so far has presented evidence the importance of relative income and consumption status for the saving and consumption behavior of households both for the domestic and international cases. the theoretical literature has analyzed the case for domestic relative consumption status exclusively. My innovation here is twofold. First, I analyze concern for relative status for the cases where the reference 
group is either domestic or international. Second, I use an endogenous growth model with endogenous rates of time preference, which allows me to analyze the growth implications of concern for status in a setting in which I do not have to arbitrarily assume identical rates of time preference to ensure the existence of a steady state equilibrium.

My results suggest that not every household benefits from "globalization" defined to be a move to a state where relative status concerns are globalized. Those agents who need to increase their savings to raise their relative status may experience welfare losses. I do show, however, that across steady states globalization increases the rate of growth of both countries above their autarkic levels. 


\section{Figure 3.1: Simulated Results Consumption Time Path}
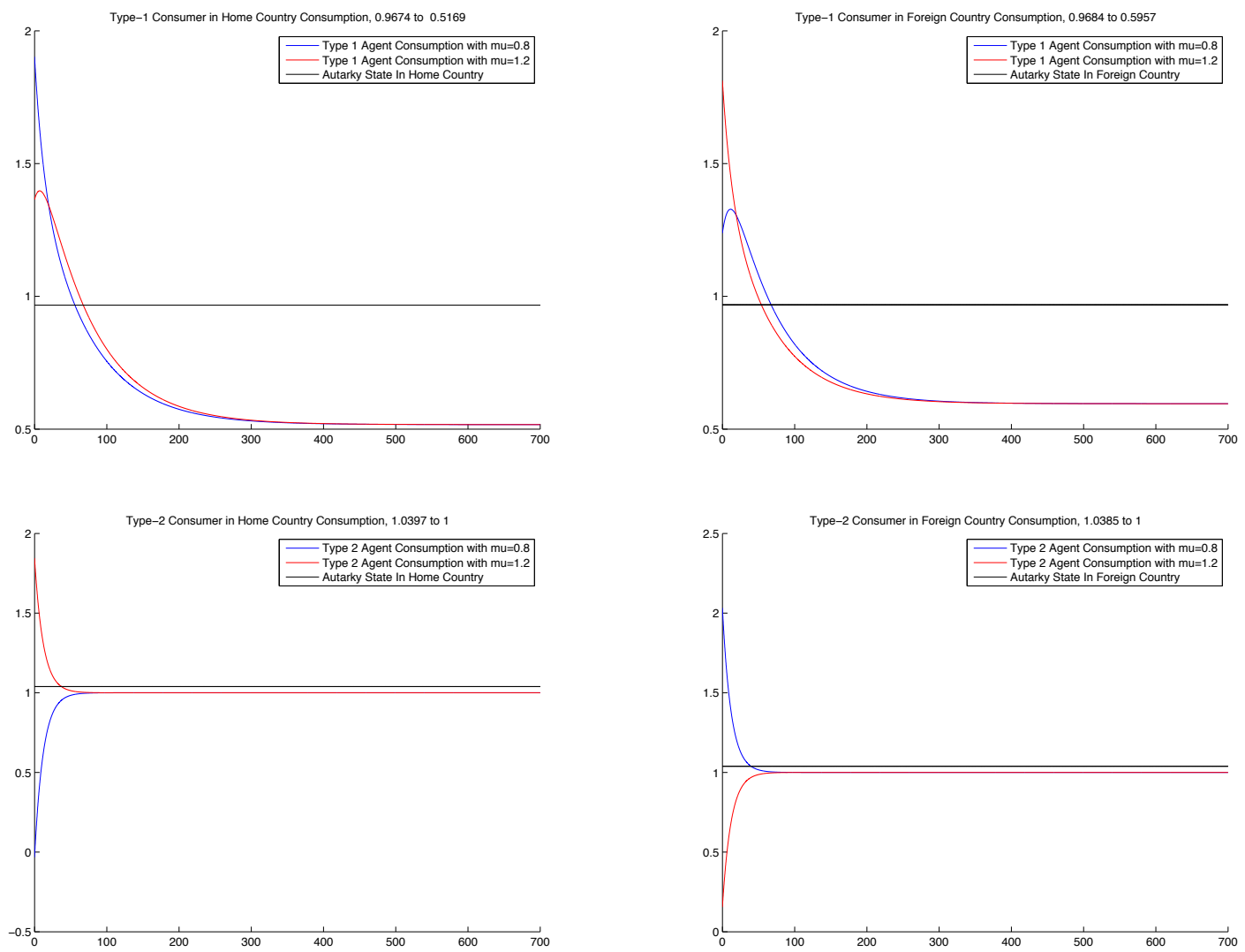
Figure 3.2: Simulated Results $\phi$ Time Path
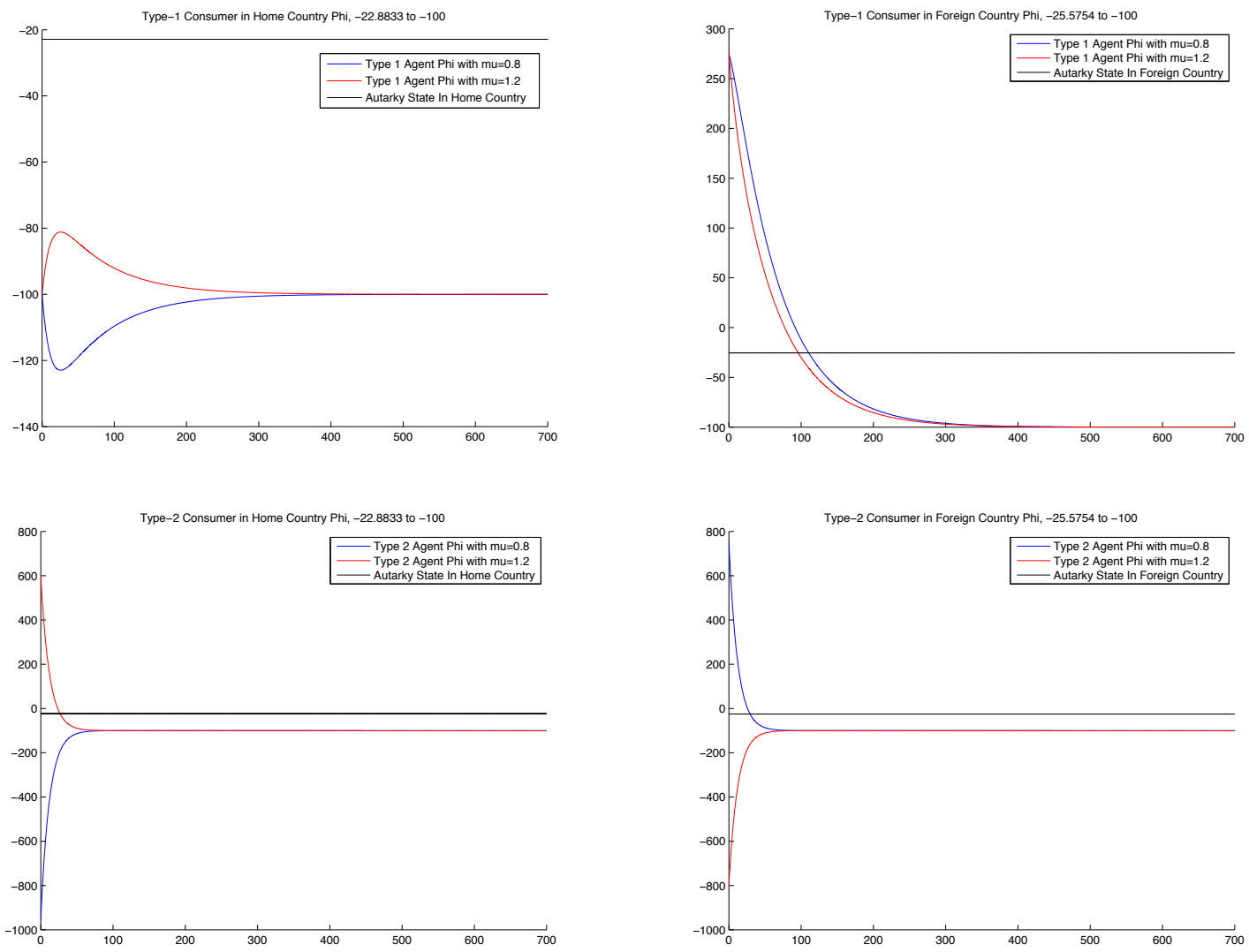
Figure 3.3: Simulated Results of Time paths of $f$ and $\gamma$
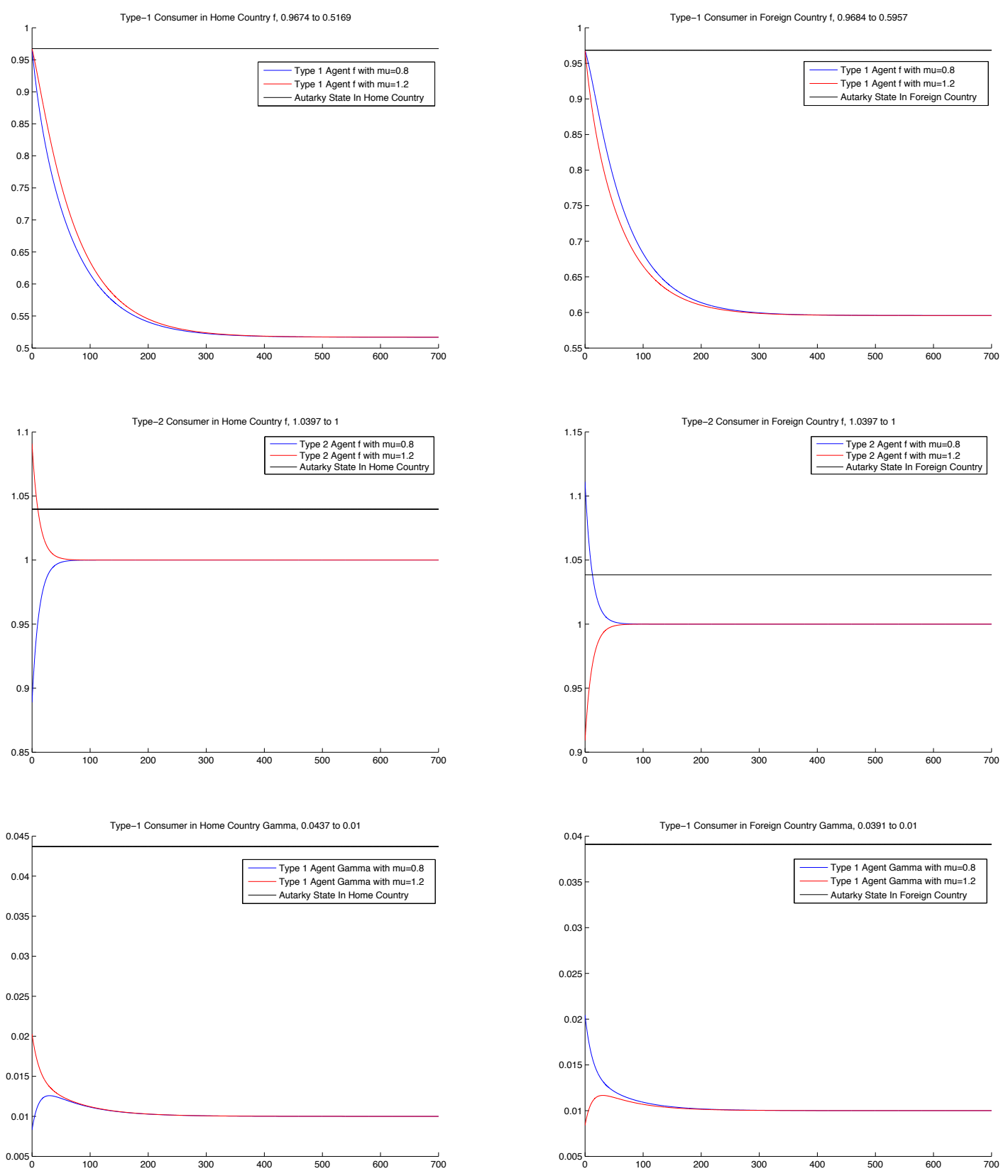


\section{BIBLIOGRAPHY}

Acemoglu, Daron, Finkelstein, Amy, \& Notowidigdo, Matthew J. 2013. Income and health spending: evidence from oil price shocks. The review of Economics and Statistics, 95(4), 1079-1095.

Adu, George. Natural resource abundance and economic growth: the case of Ghana.

Alm, James, \& Liu, Yongzheng. 2013. Did China's TaxforFee Reform Improve Farmers' Welfare in Rural Areas? The Journal of Development Studies, 49(4), 516-532.

Alpizar, Francisco, Carlsson, Fredrik, \& Johansson-Stenman, Olof. 2005. How much do we care about absolute versus relative income and consumption? Journal of Economic Behavior \& Organization, 56(3), 405-421.

Anthony. 2005. Happiness: Lessons From A New Science By Anthony. London: Allen Lane.

Arellano, M, \& Bond, S. 1991. Some tests of specification for panel data: Monte Carlo evidence and an application to employment equations. The Review of Economic Studies.

Arellano, M, \& Bover, O. 1995. Another look at the instrumental variable estimation of error-components models. Journal of econometrics, 68(1), 29-51.

Atkinson, A B, \& Brandolini, A. 2001. Promise and pitfalls in the use of" secondary" data-sets: Income inequality in OECD countries as a case study. Journal of Economic Literature.

Aus dem Moore, Nils, \& Kasten, Tanja. 2009. Do wages rise when corporate tax rates fall? Difference-in-Differences Analyses of the German Business Tax Reform 2000.

Babones, S J, \& Rivadulla, MJ Alvarez. 2007. Standardized Income Inequality Data for Use in CrossNational Research. Sociological Inquiry.

Bach, Steffen, Blöchliger, Hansjörg, \& Wallau, Dominik. 2009. The Spending Power of Sub-Central Governments. OECD Economics Department Working Papers.

Barenstein, Matias, \& de Mello, Luiz R. 2001. Fiscal decentralization and governance: A cross-country analysis. International Monetary Fund Working Paper.

Barunik, Jozef, Kocenda, Evzen, \& Vacha, Lukas. 2013. Gold, oil, and stocks.

Beck, Nathaniel, \& Katz, Jonathan N. 1996. Nuisance vs. substance: Specifying and estimating time-series-cross-section models. Political Analysis, 6(1), 1-36. 
Benabou, Roland. 1996. Inequality and Growth. NBER Macroeconomics Annual, 11(Jan.), 11-74.

Bertrand, Marianne, \& Morse, Adair. 2013. Trickle-Down Consumption.

Blanchard, Olivier, \& Shleifer, Andrei. 2001. Federalism with and without political centralization: China versus Russia. IMF Staff Papers, 48(Special Issue), 171179 .

Blanchflower, David G, \& Oswald, Andrew J. 2004. Well-being over time in Britain and the USA. Journal of Public Economics, 88(7), 1359-1386.

Blanco, Luisa, Nugent, Jeffrey, \& Veenstra, Graham. 2012. Effects of Natural Resource Abundance on Institutions: Which, Where and When? School of Public Policy Working Papers, Paper 20.

Blöchliger, Hansjörg, \& Rabesona, Josette. 2009. The fiscal autonomy of sub-central governments: An update. OECD Working Papers on Fiscal Federalism.

Blundell, R, \& Bond, S R. 2002. Initial Conditions and Moment Restrictions in Dynamic Panel Data Models.

Brückner, Markus, Chong, Alberto, \& Gradstein, Mark. 2012. Estimating the permanent income elasticity of government expenditures: Evidence on Wagner's law based on oil price shocks. Journal of Public Economics, 96(11), 1025-1035.

Bulte, Erwin H, Damania, Richard, \& Deacon, Robert T. 2005. Resource intensity, institutions, and development. World Development, 33(7), 1029-1044.

Cameron, A Colin, \& Trivedi, Pravin K. 2005. Microeconometrics: Methods and Applications. Cambridge University Press.

Carrion-i Silvestre, J L, Espasa, M, \& Mora, T. 2008. Fiscal decentralization and economic growth in Spain. Public finance review, 36(2), 194-218.

Carroll, Christopher D, Overland, Jody, \& Weil, David N. 1997. Comparison utility in a growth model. Journal of Economic Growth, 2(4), 339-367.

Castelló, Amparo, \& Doménech, Rafael. 2002. Human capital inequality and economic growth: some new evidence. The Economic Journal, 112(478), C187-C200.

Cheema, G S, \& Rondinelli, D. 2007. From government decentralization to decentralized governance. Decentralizing Governance. Emerging Con cepts and Practices, Washington, S, 1, 20.

Chong, A, \& Calderon, C. 2000. Institutional quality and income distribution. Economic Development and Cultural Change, 48(4), 761-786. 
Chong, A, \& Gradstein, M. 2007. Inequality and institutions. The review of Economics and Statistics, 89(3), 454-465.

Clark, Andrew E, Frijters, Paul, \& Shields, Michael A. 2008. Relative income, happiness, and utility: An explanation for the Easterlin paradox and other puzzles. Journal of Economic Literature, 95-144.

Clark, Tom S, \& Linzer, Drew A. 2012. Should I Use Fixed or Random Effects?

Cole, Harold L, Mailath, George J, \& Postlewaite, Andrew. 1992. Social norms, savings behavior, and growth. The journal of political economy, 1092-1125.

Cooper, Ben, Garcia-Penalosa, Cecilia, \& Funk, Peter. 2001. Status effects and negative utility growth. The Economic Journal, 111(473), 642-665.

Dabla-Norris, Era. 2005. Issues in Intergovernmental Fiscal Relations in China. International Monetary Fund Working Paper.

Dabla-Norris, Era. 2006. The Challenge of Fiscal Decentralisation in Transition Countries. Comparative Economic Studies, 48(1), 100-131.

Davoodi, H, \& Zou, H. 1998. Fiscal decentralization and economic growth: A crosscountry study. Journal of Urban Economics, 43(2), 244-257.

Department of Comprehensive Statistics. 1999. Comprehensive statistical data and materials on 50 years of new china. National Bureau of Statistics: China Statitics Press.

Di Tella, Rafael, MacCulloch, Robert J, \& Oswald, Andrew J. 2003. The Macroeconomics of Happiness. The Review of Economics and Statistics, 85(4), 809-827.

Dolan, Paul, Peasgood, Tessa, \& White, Mathew. 2008. Do we really know what makes us happy? A review of the economic literature on the factors associated with subjective well-being. Journal of Economic Psychology, 29(1), 94-122.

Donald, S G, \& Lang, K. 2007a. Inference with difference-in-differences and other panel data. The review of Economics and Statistics, 89(2), 221-233.

Donald, S G, \& Lang, K. 2007b. Inference with difference-in-differences and other panel data. The review of Economics and Statistics, 89(2), 221-233.

Easterlin, Richard A. 1974. Does economic growth improve the human lot? Some empirical evidence. Nations and households in economic growth, $\mathbf{8 9 .}$

Easterlin, Richard A. 1995. Will raising the incomes of all increase the happiness of all? Journal of Economic Behavior \&S Organization, 27(1), 35-47. 
Ebert, Udo, \& Moyes, Patrick. 2000. An axiomatic characterization of Yitzhaki's index of individual deprivation. Economics Letters, 68(3), 263-270.

Encinosa, III, William E, Gaynor, Martin, \& Rebitzer, James B. 2007. The sociology of groups and the economics of incentives: Theory and evidence on compensation systems. Journal of Economic Behavior \& Organization, 62(2), 187-214.

Epstein, Larry G, \& Hynes, J Allan. 1983. The rate of time preference and dynamic economic analysis. The Journal of Political Economy, 611-635.

Erb, C, \& Harvey, C. 2012. The Golden Dilemma. Available at SSRN 2078535.

Estevadeordal, Antoni, \& Taylor, Alan M. 2013. Is the Washington Consensus Dead? Growth, Openness, and the Great Liberalization, 1970s-2000s. The review of Economics and Statistics, 95(5), 1669-1690.

Fafchamps, Marcel, \& Shilpi, Forhad. 2009. Isolation and subjective welfare: evidence from South Asia. Economic Development and Cultural Change, 57(4), 641-683.

Falk, Armin, \& Knell, Markus. 2004. Choosing the Joneses: Endogenous goals and reference standards. The Scandinavian Journal of Economics, 106(3), 417-435.

Ferrer-i Carbonell, Ada. 2005. Income and well-being: an empirical analysis of the comparison income effect. Journal of Public Economics, 89(5), 997-1019.

Fisher, Walter H, \& Hof, Franz X. 2000. Relative consumption, economic growth, and taxation. Journal of Economics, 72(3), 241-262.

Garcia-Penalosa, Cecilia, \& Turnovsky, Stephen J. 2008. Consumption Externalities: A Representative Consumer Model When Agents Are Heterogeneous. Economic Theory, 37(3), 439-467.

Greene, William H. 2011. Econometric Analysis. Pearson College Division.

Gregorio, José De, \& Lee, Jong Wha. 2002. Education and Income Inequality: New Evidence From CrossCountry Data. Review of Income and Wealth, 48(3), $395-416$.

Gupta, S, Davoodi, H, \& Alonso-Terme, R. 2002. Does corruption affect income inequality and poverty? Economics of Governance, 3(1), 23-45.

Hall, Robert E, \& Jones, Charles I. 1999. Why do some countries produce so much more output per worker than others? The quarterly journal of economics, 114(1), 83-116. 
Higgins, Matthew, \& Williamson, Jeffrey G. 1999. Explaining Inequality the World Round: Cohort Size, Kuznets Curves, andOpenness.

Holtz-Eakin, Douglas, Newey, Whitney, \& Rosen, Harvey S. 1988. Estimating Vector Autoregressions with Panel Data. Econometrica, 56(6), 1371.

Imbens, G, \& Wooldridge, J. 2007. What's new in econometrics. Lecture Notes, NBER Summer Institute.

Isham, Jonathan, Woolcock, Michael, Pritchett, Lant, \& Busby, Gwen. 2005. The varieties of resource experience: natural resource export structures and the political economy of economic growth. The World Bank Economic Review, 19(2), $141-174$.

J Solnick, Sara, \& Hemenway, David. 1998. Is more always better?: A survey on positional concerns. Journal of Economic Behavior \& Organization, 37(3), 373383.

Jin, Hehui, Qian, Yingyi, \& Weingast, Barry R. 2005. Regional decentralization and fiscal incentives: Federalism, Chinese style. Journal of Public Economics, 89(9-10), 1719-1742.

Johansson-Stenman, Olof, Carlsson, Fredrik, \& Daruvala, Dinky. 2002. Measuring Future Grandparents' Preferences for Equality and Relative Standing. The Economic Journal, 112(479), 362-383.

Kahneman, Daniel, \& Krueger, Alan B. 2006. Developments in the measurement of subjective well-being. The Journal of Economic Perspectives, 20(1), 3-24.

Kaufmann, D, Kraay, A, \& Mastruzzi, M. 2010. The worldwide governance indicators: methodology and analytical issues. World Bank Policy Research Working Paper.

Keefer, P, \& Knack, S. 2002. Polarization, politics and property rights: Links between inequality and growth. Public Choice, 111(1), 127-154.

Khaleghian, Peyvand. 2004. Decentralization and public services: the case of immunization. Social Science \&f Medicine, 59(1), 163-183.

Knack, S, \& Keefer, P. 1995. Institutions and economic performance: crosscountry tests using alternative institutional measures. Economics \& Politics, 7(3), 207227.

Kyriacou, Andreas P, \& Roca-Sagales, Oriol. 2011. Fiscal and political decentralization and government quality. Environment and Planning C: Government and Policy, 29(2), 204-223. 
Leite, Carlos, \& Weidmann, Jens. 1999. Does Mother Nature Corrupt - Natural Resources, Corruption, and Economic Growth. July.

Lin, Justin Yifu, \& Liu, Zhiqiang. 2000. Fiscal Decentralization and Economic Growth in China. Economic Development and Cultural Change, 49(1), 1-21.

Liu, Wen-Fang, \& Turnovsky, Stephen J. 2005. Consumption externalities, production externalities, and long-run macroeconomic efficiency. Journal of Public Economics, 89(5), 1097-1129.

Marmot, Michael, \& Wilkinson, Richard. 2005. Social Determinants of Health. Oxford University Press.

Martinez-Vazquez, Jorge, \& McNab, Robert. 1997 (Oct.). Fiscal decentralization, economic growth, and democratic governance. In: USAID Conference Economic Growth and Democratic Governance.

Martinez-Vazquez, Jorge, \& McNab, Robert M. 2003. Fiscal Decentralization and Economic Growth. World Development, 31(9), 1597-1616.

Mehlum, Halvor, Moene, Karl, \& Torvik, Ragnar. 2006. Institutions and the Resource Curse. The Economic Journal, 116(508), 1-20.

Montinola, G, Qian, Y, \& Weingast, B R. 1995. Federalism, Chinese style: the political basis for economic success in China. World Politics, 48(01), 50-81.

Murphy, Kevin M, Shleifer, Andrei, \& Vishny, Robert W. 1991. The Allocation of Talent: Implications for Growth. The quarterly journal of economics, 106(2), 503-530.

Narayan, Paresh Kumar, Huson, Ali Ahmed, \& Seema, Narayan. 2013. Do Momentum-Based Trading Strategies Work in Commodity Markets? Working Paper Series, Centre for Financial Econometrics, Deakin University, Melbourne, Australia, May, 1-34.

Oates, Wallace E. 1972. Fiscal federalism. Houghton Mifflin Harcourt P.

Oates, Wallace E. 1997. On the Welfare Gains from Fiscal Decentralization. Journal of Public Finance and Public Choice, 2-3, 83-92.

Obstfeld, Maurice. 1990. Intertemporal dependence, impatience, and dynamics. Journal of Monetary Economics, 26(1), 45-75.

Oswald, Andrew J, \& Blanchflower, David G. 2011. International happiness.

Qian, Y, \& Roland, G. 1999. Federalism and the soft budget constraint. The American Economic Review, 88, 1143-1162. 
Qian, Y, \& Weingast, B R. 1997. Federalism as a commitment to perserving market incentives. The Journal of Economic Perspectives, 11(4), 83-92.

Ray, Debraj. 2010. Uneven growth: a framework for research in development economics. The Journal of Economic Perspectives, 24(3), 45-60.

Riker, William H. 1964. Federalism: origin, operation, significance. Little, Brown (Boston).

Robalino, D., Picazo, O., \& Voetberg, A. 2001. Does fiscal decentralization improve health outcomes? Evidence from a cross-country analysis. World Bank Policy Research Working Paper No. 2565.

Rodríguez-Pose, Andrés, \& Tselios, Vassilis. 2009. Education And Income Inequality In The Regions Of The European Union. Journal of Regional Science, 49(3), 411437.

Rodríguez-Pose, Andrés, \& Tselios, Vassilis. 2010. Inequalities in income and education and regional economic growth in western Europe. The annals of regional science, $\mathbf{4 4}(2), 349-375$.

Rodrik, Dani. 1998. Why do More Open Economies Have Bigger Governments? Journal of Political Economy, 106(5), 997-1032.

Rojas-Romagosa, H, \& Francois, J F. 2005. The Construction and Interpretation of Combined Cross-Section and Time-Series Inequality Datasets.

Roodman, David. 2006. How to do Xtabond2: An Introduction to Difference and System GMM in Stata. SSRN Electronic Journal.

Ryder, Jr, Harl E, \& Heal, Geoffrey M. 1973. Optimal Growth with Intertemporally Dependent Preferences. The Review of Economic Studies, 40(1).

Sachs, Jeffrey D, \& Warner, Andrew M. 1999. The big push, natural resource booms and growth. Journal of development economics, 59(1), 43-76.

Sachs, Jeffrey D, \& Warner, Andrew M. 2001. The curse of natural resources. European Economic Review, 45(4), 827-838.

Sala-i Martin, Xavier, \& Subramanian, Arvind. 2003. Addressing the natural resource curse: An illustration from Nigeria.

Sauvant, Karl P, Zhao, Chen, \& Xiaoying, Huo. 2012. The Unbalanced dragon: China's uneven provincial and regional FDI performance. Columbia FDI Perspectives, Mar. 
Savoia, Antonio, Easaw, Joshy, \& McKay, Andrew. 2010. Inequality, Democracy, and Institutions: A Critical Review of Recent Research. World Development, 38(2), 142-154.

Scully, Gerald W. 1988. The institutional framework and economic development. The journal of political economy, 652-662.

Shu-Ki, T, \& Yuk-Shing, C. 1994. China's tax reforms of 1994: breakthrough or compromise? Asian Survey, 34(9), 769-788.

Smith, Adam. 1937. An Enquiry into the Nature and Causes the Wealth of Nations. New York: The Modern Library.

Solt, Frederick. 2009. Standardizing the World Income Inequality Database. Social Science Quarterly, 90(2), 231-242. SWIID Version 3.1, December 2011.

Stijns, J P C. 2005. Natural resource abundance and economic growth revisited. Resources policy, 30(2), 107-130.

Stijns, Jean-Philippe. 2006. Natural resource abundance and human capital accumulation. World Development, 34(6), 1060-1083.

Sunde, Uwe, Cervellati, Matteo, \& Fortunato, Piergiuseppe. 2008. Are all democracies equally good? The role of interactions between political environment and inequality for rule of law. Economics Letters, 99(3), 552-556.

Taillant, D. 1994. Decentralization: Local and regional government development. A literature review.

Thiessen, Ulrich. 2000 (June). Fiscal federalism in Western European and selected other countries: centralization or decentralization? What is better for economic growth? In: Ukraine on the road to Europe?

Thornton, John. 2007. Fiscal decentralization and economic growth reconsidered. Journal of Urban Economics, 61(1), 64-70.

Tiebout, C M. 1956. A pure theory of local expenditures. The journal of political economy, 64(5), 416-424.

Veblen, Thorstein. 1957. THE THEORY OF THE LEISURE CLASS. George Allen \& Unwin.

Vendrik, Maarten, \& Woltjer, Geert B. 2007. Happiness and loss aversion: Is utility concave or convex in relative income? Journal of Public Economics, 91(7), 14231448 . 
Wan, Henry. 1970. Optimal saving programs under intertemporally dependent preferences. International Economic Review, 11(3), 521-547.

Wawro, Gregory. 2002. Estimating dynamic panel data models in political science. Political Analysis, 10(1), 25-48.

Weingast, B R. 1997. The political foundations of democracy and the rule of law. American Political Science Review, 245-263.

Xie, Danyang, Zou, Heng-fu, \& Davoodi, Hamid. 1999. Fiscal Decentralization and Economic Growth in the United States. Journal of Urban Economics, 45(2), $228-239$.

Zhang, T., \& Zou, H. 1998. Fiscal decentralization, public spending, and economic growth in China. Journal of Public Economics, 67(2), 221-240.

Zhao, Wei. 2012. Economic inequality, status perceptions, and subjective well-being in China's transitional economy. Research in Social Stratification and Mobility, 30(4), 433-450. 
VITA

YI DING

October, 1988

Born, Chongqing, China

2009

B.A., Info. Management and Info. System

Renmin University of China

Beijing, China

2009-2014

Doctoral Student

Florida International University

Miami, Florida

2009-2014

Teaching Assistant

Florida International University

Miami, Florida 